BNWL-B-341

\title{
PRELIMINARY SAFETY ANALYSIS REPORT FOR THE PNL NEUTRON MULTIPLIER
} FACILITY
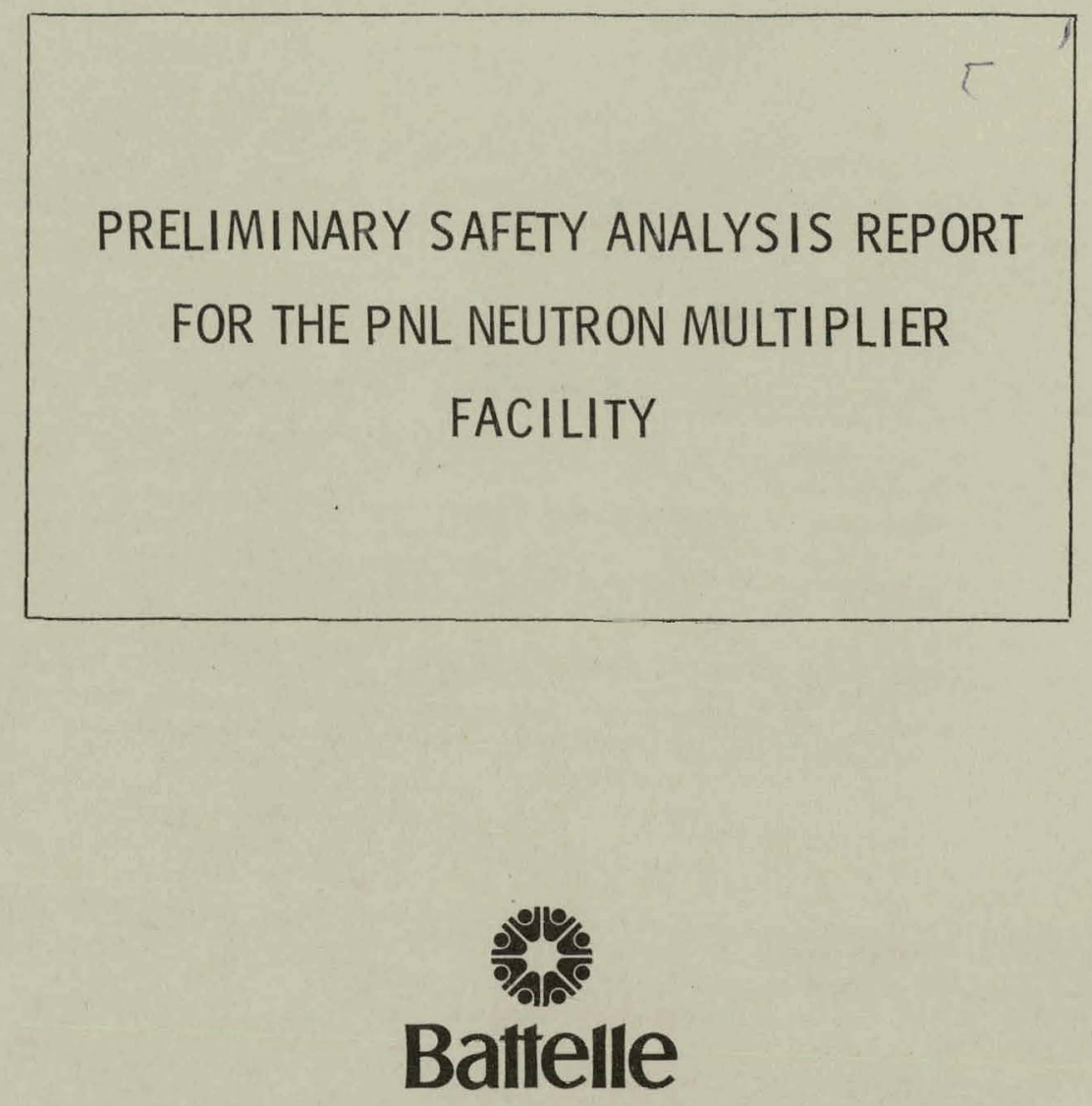

Pacific Northwest Laboratories

Richland, Washington 99352

\section{JANUARY 1974}

This report is intended primarily for internal use by the sponsoring organization and Battelle.

Prepared for the U.S. Atomic Energy

Commission under Contract AT(45-1):1830 


\section{DISCLAIMER}

This report was prepared as an account of work sponsored by an agency of the United States Government. Neither the United States Government nor any agency Thereof, nor any of their employees, makes any warranty, express or implied, or assumes any legal liability or responsibility for the accuracy, completeness, or usefulness of any information, apparatus, product, or process disclosed, or represents that its use would not infringe privately owned rights. Reference herein to any specific commercial product, process, or service by trade name, trademark, manufacturer, or otherwise does not necessarily constitute or imply its endorsement, recommendation, or favoring by the United States Government or any agency thereof. The views and opinions of authors expressed herein do not necessarily state or reflect those of the United States Government or any agency thereof. 


\section{DISCLAIMER}

Portions of this document may be illegible in electronic image products. Images are produced from the best available original document. 


\title{
NOTICE
}

The report was prepared as an account of work sponsored by the United States Government. Neither the United States nor the United States Atomic Energy Commission, nor any of their employees, nor any of their contractors, subcontractors, or their employees, makes any warranty, express ur implied, or assumes any legal lidbility or responsibility for the accuracy, completeness or usefulness of any information, apparatus, product or process disclosed, or rcpresents that its use would not infringe privately owned righis.

\author{
PACIFIC NORTHWEST LABORATORY \\ operated by \\ BATTELLE \\ for the \\ U.S. ATOMIC ENERGY COMMISSION \\ Under Contract AT(45-1)-1830
}

\author{
Printed in llip I luited states of Anerica \\ Available from \\ National Technical Information Service \\ U.S. Department of Commerce \\ 5285 Port Royal Road \\ Springfield, Virginia 22151 \\ Price: Printed Copy \$5.45; Microfiche $\$ 1.45$
}




\section{PRELIMINARY SAFETY ANALYSIS REPORT FOR \\ THE PNL NEUTRON MULTIPLIER FACILITY}

\section{January 1974}

This report was prepared as an account of work sponsored by the United States Government. Neither spo United States nor the United States Atomic Energy Commision theirission, nor any of their employed, employees, their contractors, subcontractors, or theis emples any legal liability or responsibility for the accuracy, com pleteness or usefulness of any information, apparatus, producl or process disclosed, or represents that its use would not infringe privately owned rights.

by

R. J. Hall

and

H. G. Rieck, Jr. 


\section{TABLE OF CONTENTS}

I. INTRODUCTION. ..................... Page

II. SUMMARY AND CONCLUSIONS . . . . . . . . . . . . . 2

III. NUCLEAR SAFETY LIMITS AND BASES . . . . . . . . . . . 4

A. NUCLEAR SAFETY LIMITS ............. 4

B. BASES .................. . . 4

IV. DESCRIPTION . . . . . . . . . . . . . 5

A. SITE. .................. 5

B. FACILITY. . . . . . . . . . . . 5

1. General ............... . 5

2. Structure ............... 7

3. Pool.................. . . 7

4. Water Processing System ......... . 8

C. NEUTRON MULTIPLIER. . . . . . . . . . . 10

1. General .............. . 10

2. ${ }^{252}$ Cf Neutron Source. . . . . . . . 12

3. Fuel Rods . . . . . . . . . . . . 12

4. Fuel Region............... . . 12

5. Grid Plates and Support Structure . . . . . 13

6. Source Drive. . . . . . . . . . . 13

7. Central Irradiation Tube. . . . . . . 15

8. External Irradiation Tubes. . . . . . . . 16

9. Special Experiment Central Irradiation Tube . . 16

D. SAMPLE AND SOURCE HANDLING. . . . . . . . . . 17

1. Sample Handling . . . . . . . . . . . 17

2. Source Handling ............. 18 
V. ORGANIZATION AND ADMINISTRATIVE CONTROLS. . . . . . 19

A. RESPONSIBLITY FOR FACILITY. . . . . . . . . 19

B. SECURITY CONTROL. ............. 20

C. EXPERIMENT PLANS, REVIEWS AND AUTHORIZATIONS. . . . 21

D. TRAINING PROGRAM. ............... 21

E. ADMINISTRATIVE LIMITS AND CONTROLS ON SAMPLES . . . 22

1. Sample Log. . . . . . . . . . . . 22

2. Sample History. . . . . . . . . . . 22

3. Sample Verification (Enriched U Sample) . . . 22

F. FACILITY CHANGES. . . . . . . . . . . 23

G. QA LEVEL REQUIREMENTS .............. 23

VI. PRELIMINARY SAFETY ANALYSIS . . . . . . . . . . 24

A. GENERAL SAfETY PLAN ............ 24

B. NEUTRON MULTIPLIER CHARACTERISTICS. . . . . . . 24

C. NORMAL OPERATING CONDITIONS ......... . 29

D. PARAMETERS UNDER NORMAL OPERATING CONDITIONS. . . . 32

E. ABNORMAL AND ACCIDENT CONDITIONS. ....... 41

F. ADDITIONAL NMF DESIGN FEATURES BEARING ON SAFETY. . 47

G. PLANS FOR EVENTUAL SHUTDOWN AND DISPOSAL OF THE NMF 49

VII. CONSEQUENCES OF NUCLEAR ACCIDENTS . . . . . . . . 50

VIII. REFERENCES. .................... 52

APPENDICES. . . . . . . . . . . 53 
PRELIMINARY SAFETY ANALYSIS REPORT FOR

THE BNW NEUTRON MULTIPLIER FACILITY

\section{INTRODUCTION}

The Neutron Multiplier Facility (NMF) is designed to produce a high flux for neutron irradiation of various samples. Irradiations made in the NMF will be of two basic types: 1) irradiation of organic and inorganic environmental samples for the purpose of neutron activation analysis, and 2) irradiation of a maximum of 4 grams of ${ }^{235} U$ for on-7ine mass spectrometry of fission products. A maximum of seven sample irradiation positions (one in, and six on the periphery of, the neutron multiplier) will be provided.

The basic components of the neutron multiplier will be a ${ }^{252} \mathrm{Cf}$ neutron source and a surrounding subcritical uranium assembly which multiplies the source neutrons through fission. The neutron multiplier is designed to remain subcritical under all normal and credible abnormal conditions. The principle of the neutron multiplier is that a subcritical assembly of fissile material can substantially multiply the number of neutrons emanating from a neutron source. Reactor theory shows that the mere addition of neutrons to a multiplying assembly, all other parameters remaining constant, will not affect criticality (i.e., change the reproduction factor), since the reproduction factor depends on the interaction of neutrons with matter, not on the initial number of neutrons (the source). The simple addition of a pure neutron source has no bearing on how the neutrons will subsequently interact. The neutron multiplier will remain subcritical regardless of the presence or absence of a neutron source. 
The NMF will be housed in an annex attached to the 329 Building. This location was chosen as the appropriate site because of the related counting facilities in the existing building. Many of the activated products, after irradiation by the neutron multiplier, will have very short half lives; it is therefore essential that counting of these products be done immediately. Location of the NMF close to the existing counting laboratories will allow these counting activities to start with a minimal time delay.

The neutron multiplier will be installed at the bottom of a 20 foot deep, 5 foot diameter pool located in the floor of the one room annex. The pool water is used for radiation shielding of the neutron multiplier. The annex will also contain the following support equipment: pool water processing items, electric hoist, laminar flow hood, standard laboratory hood, laboratory bench, and heating and air conditioning units.

\section{SUMMARY AND CONCLUSIONS}

The NMF will provide thermal neutrons for irradiation of two basic types of samples. These are: 1) environmental samples and 2) a 4 gram maximum sample of fully enriched uranium. The latter will be used to produce fission products for on-line mass spectrometry. The Neutron Multiplier will produce thermal neutrons by fission multiplication and subsequent moderation of neutrons from a ${ }^{252} \mathrm{Cf}$ source. The NMF is designed for use of a $100 \mathrm{mg}$ ${ }^{252} \mathrm{Cf}$ source. The fuel for the neutron multiplier is $93 \%{ }^{235} \mathrm{U}$ enrlched uranium. The thermal neutron flux available from the neutron mulliplier will be of the order of $10^{10}$ neutrons $/ \mathrm{cm}^{2} \mathrm{sec}$.

The NMF will be a subcritical facilfty. Under normal operating conditions the neutron multiplier will have a $k_{\text {eff }}$ in the range $0.92-0.97$ 
depending on irradiation tube configuration and sample characteristics. The neutron multiplier will be located at the bottom of a 20 foot deep pool of water. Physical barriers will prevent rearrangement of fuel. The nuclear parameters of the neutron multiplier are such that no temperature or water density (voiding or flooding) effects can result in criticality. Non-exempt* fissionable material in the facility will be limited to that required to fuel the neutron multiplier plus 4 grams of enriched uranium in the form of a sample for irradiation. The NMF will be a locked facility. Signs stating that fissionable material shall not be brought into the facility without authorization of the facility supervisor shall be posted at each entrance. At least double contingency protection against criticality will either exist due to design or be provided by administrative control:

Only personnel who have received specific training shall be permitted to operate or maintain the neutron multiplier. Radiation levels shall be such that personnel may remain in the immediate area while the neutron multiplier is operating. In the experiment involving irradiation of a $\leq 4$ gram sample of fulty enriched uranium a highly collimated vertical beam with a level of approximately $150 \mathrm{mrem} / \mathrm{hr}$ could be produced. In this instance physical controls or temporary shielding, as required, will be employed to limit exposure. ${ }^{41}$ Ar production in the irradiation tubes was considered and found not to create a hazard. The fuel and ${ }^{252} \mathrm{Cf}$ source wi11 be encapsulated to prevent contamination spread. Monitoring and administrative

*Natural uranium and thorium are exempt. 
control on sample and source handling will reduce the hazards from such operations to an acceptable level.

It is concluded that the NMF can be built and operated wt thout creating an unacceptable risk to either operating personnel or the public.

\section{NUCLEAR SAFETY LIMITS AND BASES}

A. NUCLEAR SAFETY LIMITS

Use of fissionable materials in the NMF shall be controlled by Criticality Safety Specifications based on the following fundamental Nuclear Safety Limits:

1. The only fissionable materials permitted in the NMF are uranium and thorium.

2. The Neutron Multiplier fuel shall either be a) on the Neutron Multiplier grid plate in the configuration shown in Drawing (number to be specified in FSAR) or $b$ ) in units of no more than $45 \%$ of a critical mass, credit being taken for form and geometry.

3. A maximum of 4 grams of non-exempt* fissionable material in addition to the Neutron Multiplier fuel shall be permitted in the NMF.

\section{B. BASES}

LIMIT 1 - This NSL limits the fissionable material permitted in the NMF to only that having no greater hazard than assumed in the preliminary safety analysis.

LIMIT 2 - a): When the Neutron Multiplier fuel is on the grid plate in the configuration shown in Drawing (number to be specified in FSAR)

* Natural uranium and thorium are exempt. 
$k_{\text {eff }}$ shall not exceed 0.985 under credible conditions, e.g. credible sample, irradiation tube, and moderator-reflector conditions.

b) Units of no more than $45 \%$ of a critical mass would remain subcritical if double batched.

LIMIT 3 - This NSL limits the permitted samples in the NMF to assure that the $k_{\text {eff }}$ value in Limit 2 is not exceeded.

\section{DESCRIPTION}

\section{A. SITE}

The neutron multiplier will be housed in an annex which will be attached to the 329 Building near the southeast corner. The 329 Building is located in the 300 Area of the Hanford Reservation. A site description of the 300 Area is presented in BNWL-CC-1693.

\section{B. FACILITY}

\section{General}

The NMF will consist of one room containing approximately 520 square feet of floor space. The facility will house the neutron multiplier in a water-filled pool that will be 5 feet in diameter and twenty feet deep. The NMF also will contain the multiplier support equipment consisting of a water circulation pump, filter, ion exchanger, electric hoist, miscellaneous control equipment, laminar flow hood, standard laboratory benches. Supporting services which will be provided in the facility are: air conditioning, heat, sanitary water, compressed air, electric power and fire protection. A floor plan of the NMF is shown in Figure 1 . 


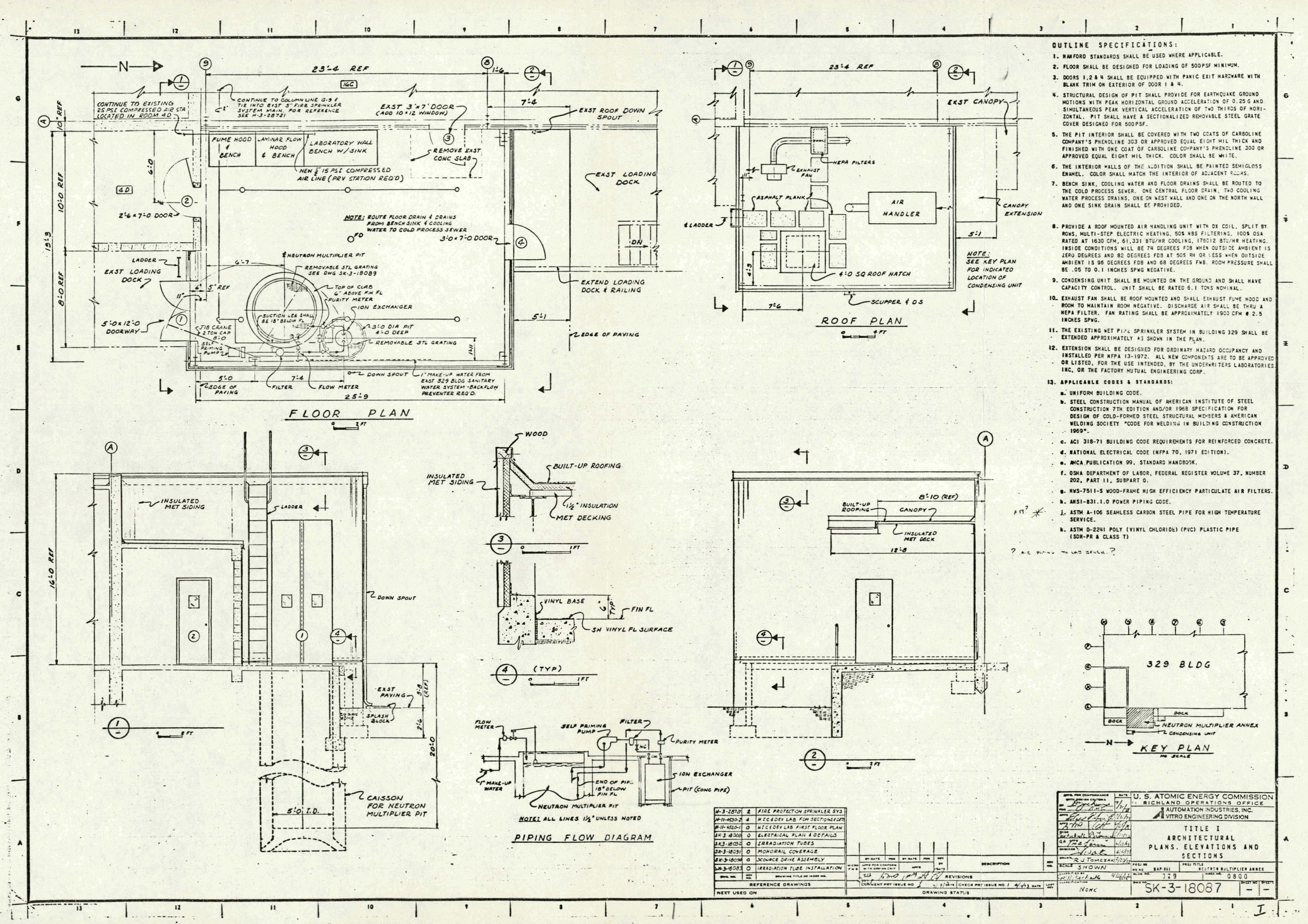




\section{Structure}

The NMF will have four doorways: 1) an emergency exit on the north side, 2) two working entrys from the 379 Puilding for laboratory personnel, and 3) double doors opening to the southeast corner loading dock. All doors will be provided with viewing ports. A hatch will be provided in the roof directly over the multiplier pool to facilitate initial loading of the ${ }^{252} \mathrm{Cf}$ source into the pool. The design wind loading of the building will conform to Hanford Standards and the UBC. Ventilation for the facility will be provided by a "oncethrough" system with exhaust air undergoing single stage HEPA filtration. The ventilation system will draw afr through the HEPA filter. which will result in a slight negative pressure th the NMF under normal operating condttions.

3. Pool

The neutron multiplier will be located at the bottom of a 5 foot diameter, 20 foot deep water-tight pit located in the southeast corner of the NMF. The pit will be constructed of standard density concrete. The structural design of the pit provides for earthquake ground motions with peak horizontal ground accelerations of $0.25 \mathrm{~g}$ and a simultaneous peak vertical acceleration of two thirds the horizontal. A dynamic analysis of the pit structure will be made during final design of the NMF. The pit will have a $6^{\prime \prime}$ htgh concrete curb around its perimeter and will have a steel grale covering with removable sections. The removable sections shall have locking provisions. The grate is designed for 500 pound $/ \mathrm{ft}^{2}$ 
loading. The grate layout is shown in Figure 2. The pit interior will be coated to prevent leaching from the concrete into the pool water.

\section{Water Processing System}

The neutron multiplier pool water will be effectively isolated.

There will be no drain connection from the pool to any 300 area sewer system. Make-up water for the pool will come from the sanitary cold water system; however, a back flow preventer will be installed in the make-up line. Opening of a normally-closed, manually-operated valve w11l be required to add make-up water. A float switch will operate a valve in series with the manual valve to close the water supply line when the required water level is attained. Low water level w+1l be signaled by an alarm. A $50 \mathrm{gpm}$ pump with inlet 18" below the top of the pool and discharge near the bottom of the pool will be provided to circulate the pool water. The water will be circulated through a filter, and by selection of the proper valving, through an fon exchange column for clean up. The ftlter and ion exchange column will serve severai purposes: 1) maintenance of water clarity to avoid restriction of the view of the neutron multiplier, 2) maintenance of high water purity to minimize the rate of corrosion of the aluminum neutron multiplier components, 3) removal of the trace quantity of radioactive material which could be present in the pool water. The latter activity will be essentially all ${ }^{24} \mathrm{Na}$. A beta emitter with a 15 hour half life, ${ }^{24} \mathrm{Na}$ is produced by the $(n, \alpha)$ reaction of fast neutrons with ${ }^{27} \mathrm{Al}$. 
A water flow meter, and temperature and conductivity probes w w 11 be installed to monitor the process system components and the water condition.

\section{NEUTRON MULTIPLIER}

\section{General}

The neutron multiplier will be secured on a support structure which will be fastened to studs embedded in the pool.floor. The fuel region of the neutron multiplier will have the shape of a vertical annulus. Sample irradiation tubes can be installed in the center and along the outside lateral surface of the neutron multiplier. The multiplier is turned "on" and "off" by remotely moving an approximately $100 \mathrm{mg}{ }^{252} \mathrm{Cf}$ source two feet into and out of a favorable position for neutron interaction with the fuel region. The neutron multiplier, which will, when on, have a maximum heat output of approximately 2-10 watts above the ${ }^{252} \mathrm{Cf}$ heat output of approximately 4 watts, is cooled by natural convection. The maximum height of the fuel region will be approximately 50 inches above the floor of the pool, leaving approximately $151 / 2$ feet of water above the neutron multiplier. The fuel region of the neutron multiplier will consist of four elements containing a total of approximately 280 fuel rods: The rods will be aluminum-clad uraniumaluminum alloy. Essentially all exposed metal in the vicinity of the neutron multiplier will be aluminum. Periodic inspections will be made to assess aluminum corrosion. A conceptual drawing of the neutron multiplier is given in Figure 3 . 


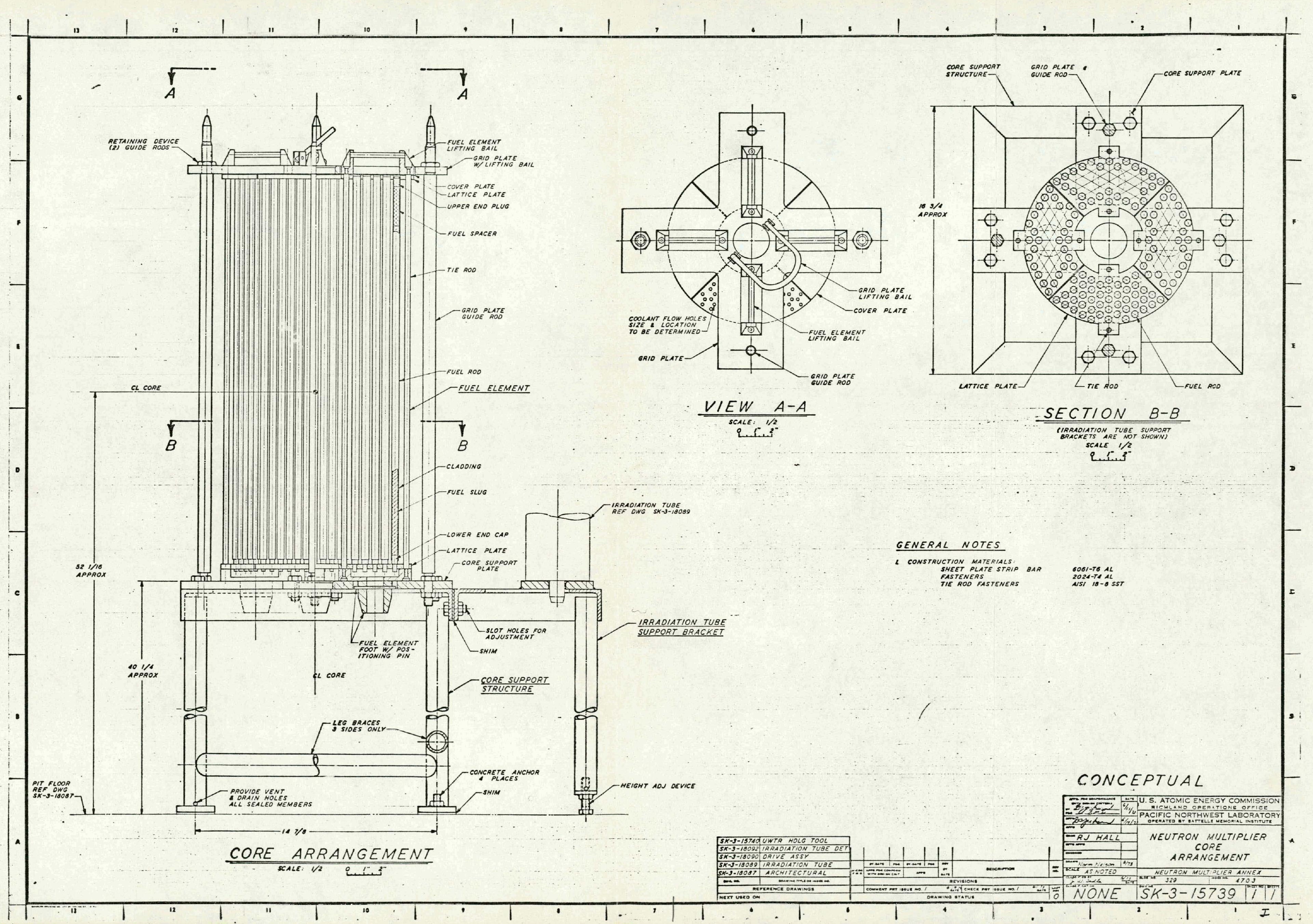




\section{2. ${ }^{252} \mathrm{Cf}$ Neutron Source}

The neutron multiplier will be activated (turned on) by a ${ }^{252} \mathrm{Cf}$ source which produces neutrons by spontaneous fission. The yield of ${ }^{252} \mathrm{Cf}$ is $2.34 \times 10^{12}$ neutrons/sec-gm. The NMF is designed for a $100 \mathrm{mg}{ }^{252} \mathrm{Cf}$ source. The source strength is a design parameter mainly in the sense that it affects the shielding required for the NMF. A two or three times larger source could be used if experimental verification demonstrates that the shielding is adequate. The heat output of ${ }^{252} \mathrm{Cf}$ is 39 watts/gram. The ${ }^{252} \mathrm{Cf}$ source will be doubly encapsulated in stainless steel to control contamination potential.

\section{Fuel Rods}

The fuel rods will be approximately .4 inches OD by 21 1/2 inches long. The fuel will be uranium-aluminum alloy. The uranium will be $93.14 \%{ }^{235} U$ enriched. The uranium wt11 represent $28 w t \%$ of the fuel, resulting in a uranium density of $1 \mathrm{~g} / \mathrm{cc}$. The fuel region of the rod will be .3" diameter by 20.6 " long. The length will be made up by 3 or more fuel segment.s. The rod cladding will be 40 mil minimum wall thickness type 1100 aluminum seamless tubing. The rod will be sealed by welded end plugs, top and bottom.

\section{Fuel Region}

The fuel region of the neutron multiplier will be annular in shape with an IR of $21 / 2^{\prime \prime}$ and an effective OR of approximately 6". The fuel rods will be fixed in a hexagonal lattice in four fuel elements which will make up the fuel region. The lattice will maintain approximately $200 \mathrm{mtls}$ of water between fuel pins. Each fuel element 
wi1l have positioning devices on the bottom for insertion and alignment of the element in the bottom grid plate. A bale will be provided on top of each fuel element for attachment to a handling device.

5. Grid Plates and Support Structure

The four fuel elements will be supported and aligned in an annulus by an aluminum bottom grid plate which will be attached to an aluminum grid plate support structure. The grid plate support structure will be fastened to studs set in the pool floor. The portion of the neutron multiplier interior to the fuel region annulus witl be water. A hole in the bottom grid plate will allow the ${ }^{252} \mathrm{Cf}$ source to be raised along the annulus axis from a position below the grid plate to a position just below the horizontal midline of the fuel region. An aluminum top grid plate, whose weight will be wholly supported from the grid plate support structure, will be fastened above the fuel elements. The supports for the six peripheral sample irradiation tubes will also attach to the grid plate support structure.

6. Source Drive

In the "off" position the ${ }^{252} \mathrm{Cf}$ source will be approximately 2 feet below the fuel region of the neutron multiplier. In the "on" position the source is raised vertically along the axial centerline of the neutron multiplier to a point approximately 1 inch below the midline of the fuel region. The electrically operated source drive unit will be located out of the water above the pool. A conceptual drawing of the source drive unit is given in Figure 4 . The source positioning mechanism which will be attached to the source 
drive will be a long rod which extends down to below the neutron multiplier. At this point an arm will extend under the grid plate to the centerline of the neutron multiplier. The ${ }^{252} \mathrm{Cf}$ source will sit in a cup located on the end of a vertical extension at the end of the arm. The source will be held in position along the axis of the neutron multiplier by a mechanical guide. A clutch arrangement will provide slippage of the source positioning mechanism in the event that unusual resistance is encountered. By defeating the action of the lower limit switch on the source drive the source positioning mechanism may be lowered to the pool floor to clear its positioning guide and rotated horizontally to a position near the pool wall to facflitate loading and unloading of the ${ }^{252} \mathrm{Cf}$ source. The latter will not be a routine operation. The speed of the source drive will be approximately 10 inches/minute. Source postion may be read by observation of a scale and pointer on the source drive. Limit switches will define the limits of travel of the source. Although the source drive unit will be normally electrically operated, it. can be manually operated by means of a handwheel.

7. Central Irradiation Tube

The central irradiation tube will be a wet (water filled) tube. Holes in the tube will allow circulation of pool water. The OD of the aluminum tube will be 2 inches and the wall thickness will be a nominal 35 mils. The tube will be closed by a perforated metal disk welded in place approximately 1 inch above the horizontal centerline of the fuel region. Positive vertical and horizontal positioning of the tube will be provided by a positioning collar 
which will seat on the upper grid plate of the neutron multiplier. The tube will extend up to 5 inches above the steel grid on the top of the pool. The tube will be supported by an adjustable height collar secured to the steel grid.

8. External Irradiation Tubes

Six irradiation tubes will be provided along the outer lateral surface of the neutron multiplier. The tubes will have nominally 35 mils wall thickness; four tubes will be 2" OD and two will be 4" $0 D$. The tubes, which will extend from $\sim 5$ " above the top of the steel grating over the pool to the bottom of the core, will be positively positioned at the bottom end. The external irradiation tubes will be dry and have bends to reduce radiation streaming. Ballast will be attached to the tubes to ensure negative buoyancy. Removable caps will be provided to close the tops of the irradtation tubes. The irradiation tubes will be supported at the top by collars fastened to the steel grating. The tubes may be ratsed and rotated to a position against the pool wall when not in use.

\section{Special Experiment Central Irradiation Tube}

For the special experiment involving irradiation of a $\leq 4$ gram enriched uranium sample for on-line mass spectrometry the normal wet central irradiation tube will be replaced by a drift tube containIng the uranfuin sdiliple under vacuum. The drift tube $O D$ in the neutron multiplier region will be less than or equal to 2 inches. The straight drift tube will extend to the surface of the pool where the mass analys is equipment will be located. 
D. SAMPLE AND SOURCE HANDLING

Radiation exposure can result from unloading of the irradiated sample from the neutron multiplier, operation of the spectal on-line mass spectrometer equipment, and handling the ${ }^{252} \mathrm{Cf}$ source. All activities involving potential personnel radiation exposure will be executed according to procedures designed to minimize the exposure. Appropriate shielding and remote handling techniques will be utflized where necessary to reduce exposures to tolerable levels.

1. Sample Handling

Samples will be prepared for activation in the neutron multiplier by appropriate encapsulation which will prevent spread of contamination. It is imperative that a low level of contamination be maintained to avoid adversely affecting low level counting operations conducted in the 329 Building. Detailed encapsulation techniques will be fully developed after sufficient operating experience has been gained. Radiation exposure from irradiated samples is a potential hazard arising from neutron multiplier operation. Control of this hazard will be accomplished by developing monitoring techniques for sample removal. These may involve use of a gamma detector placed adjacent to the irradiation ports or may require RM surveillance during sample removal. Experience gained in the operation will dictate the necessary procedure. Limits will be established for maximum radiation levels of samples being removed from the irradiation ports and samples in excess of this amount will require storage in the water pit or will require a small shielding cask to facilitate removal from the facility. Irradiated samples 
will not normally be stored in the water pit except in cases where exposure from the sample is above the maximum tolerable level.

In the on-line mass spectrometer experiment, radiation exposure potential is present in the neutron beam from the voided drift tube and from the mixed radiations from the isotopes at the collector or detector location on the mass spectrometer. Similar experiments being conducted at Washington State University indicate that physical control or shielding is adequate protection from the neutron beam. Radiation levels at the collector may approach $20 \mathrm{mr} / \mathrm{hr}$, and lead shielding is adequate protection from this source. Operating experience will dictate the final requirements for adequate radiation protection to personnel.

2. Source Handling

Radiation exposures can result from handling of ${ }^{252} \mathrm{Cf}$ sources outside the neutron multiplier pool. This hazard will be minimized by remote handling techniques and by the use of a small auxiliary cask if necessary. Remote handling techniques were developed and used during unloading of three ${ }^{252} \mathrm{Cf}$ sources from transportation carriers at the 329 Building. A $10 \mathrm{mg}$ source was successfully unloaded in September, 1971. Larger sources could be successfully handled using remote operations from a crane equipped with a long boom. Normally, sources are delivered in a suitable shielded cask mounted on a semttrailer which may be parked adjacent to the annex. The crane could be located at a distance to allow removal of the source from the transportation cask and subsequent loading into the neutron multi- 
plier through the opening in the roof directly above the water pit. The size of the opening would accommodate a small auxiliary transfer cask, which could be used, if requitred, to further reduce radiation exposure.

V. ORGANIZATION AND ADMINISTRATIVE CONTROL

Safety of personnel, equipment and the public will be a dominant factor in formulating organizational plans and developing and implementing administrative control of the NMF operations.

\section{A. RESPONSIBILITY FOR FACILITY}

Radiological Chemistry Section, Radiological Sclences Department, BattelleNorthwest, will be responsible for the NMF. Access to and use of the NMF will be regulated by the Facility Supervisor (or his delegated representative) who reports to the Manager of the Radiological Chemistry Section. The Facility Supervisor's responsibilities will include the following:

1. Development of standard radiation work procedures.

2. Establishment and implementation of a training program to develop and assure qualification and requalification of NMF operators.

3. Establishment and implementation of a program to maintain a high degree of physical security for the NMF.

4. Establishment of procedures to assure and record that adequate verification of the fissionable material mass of any enriched uranium sample to be used in the on-1tne mass spectrometry experiment is made prior to permitting entry of the sample into the NMF.

5. Development and maintenance of an industrial safety program to minimize hazardous working conditions. 
6. Development and maintenance of a sample log to provtde information as to what samples are in the neutron multiplier at any time.

7. Development of a procedure to minimize radiation exposure from irradiated samples during removal from the neutron multiplier.

8. Development of routine inspection programs to insure proper operation of all supporting equipment. This will include periodic radiation surveys.

\section{B. SECURITY CONTROL}

In order to minimize the probability of accidental or intentional damage, the NMF will be maintained as a restricted area. The following rules will facilitate this requirement:

1. All points of entry into the annex shall be through locked doors.

2. Routine access shail be limited to qualified NMF operators and others who have a work responsibility in the annex.

3. Visitors to the facility shall be under constant escort by a qualified NMF operator.

4. A limited number of keys will be issued.

5. Any tools required in the disassembly and/or handling of fuel elements of the neutron multiplier will be secured in a key locked location in another butlding. Control of this key, along with the key to the pool grating, will be assigned to the Safety and Nuclear Materials Management Section.

6. Any fissile material used in the on-line mass spectrometry experiment will require explicit approval of the Facility Supervisor prior to each entry into the annex. Approval will depend on restrictions 
imposed by Criticality Safety, amounts of fissile material, chemical form and method of encapsulation.

C. EXPERIMENT PLANS, REVIEWS AND AUTHORIZATIONS

Whenever a new type of sample is proposed for irradiation in the neutron multiplier it will be necessary for the scientist to secure approval of the Facility Supervisor. The proposed sample will be evaluated as to its impact on the operation of the neutron multiplier. The irradiation request will specify sample material, length of irradiation, predicted isotope formation and resulting exposure rate, and method of encapsulation. If approved by the Facility Supervisor, the sample will be scheduled for irradiation in the neutron multiplier. Samples will be inserted and/or removed from the neutron multiplier only by NMF operators. All sample irradiation authorizations will require periodic review and re-approval.

D. TRAINING PROGRAM

A training program will be organized and maintained to assure the qualification of NMF operators. This training program will be mutually developed by the Facility Supervisor and representatives of Industrial, Criticality, and Radiation Safety. It will be the responsibility of Facility Supervisor to assure that all personnel are familiar with necessary administrative and technical requirements to promote safe operation of the neutron multiplier. Each person shall be made aware of the possible consequences which may result from a failure to observe all established operational procedures. The training program shall be periodically reviewed and updated. 


\section{E. ADMINISTRATIVE LIMITS AND CONTROLS ON SAMPLES}

Samples to be irradiated in the NMF w11l need to be controlled for several reasons: 1) to prevent interference with irradiations in progress, 2) to minimize the probability of excess radiation exposure from irradiated sample handling, and 3) to minimize the probability of introduction of fissionable material in excess of the permitted amount. The following items will provide these controls.

\section{Sample Log}

When a sample is irradiated in the NMF the following information will be entered in a sample $\log ;$ a) sample description, weight, composition etc., b) history, c) duration and location of irradiation, and d) sample verification methods and results (Item $d$ will only be required for an enriched uranium sample). The sample log will be located in the NMF and will be used in the control of sample traffic through the NMF.

\section{Sample History}

The origin and treatment of a sample prior to irradiation will help establish the absence of fissionable materials. This is partfcularly true for a series of samples in which nearly uniform elemental concentrations are encountered. The scientist will therefore be requested to supply a history for each sample.

3. Sample Verification (Enriched U Sample)

Since the introduction of enriched uranium in excess of the permitted quantity could decrease the safety margin of the neutron multiplier, a special mass verification will be made for the sample used in the 
on-line mass spectrometry experiment. The type of verification will depend on the nature of the sample (e.g., simple gross weighing would be sufficient if the sample mass does not exceed 4 grams). The only restriction on the mass verification technique will be that it be adequate to detect sample fissionable material content in excess of the permitted quantity.

\section{F. FACILITY CHANGES}

Any proposed change to the neutron multiplier assembly will be reviewed by the Safety and Nuclear Materials Management (S\&NMM) Section. Any proposed changes which could affect the Bases given in Section III will require a SAR supplement.

G. QA LEVEL REQUIREMENTS

The general facility design by the A\&E shall conform to BNW QAL II-A in accordance with BNW Manual BNWL-MA-65 Revised. Controlled procurements shall conform to BNW QAP III.

Design performed by BNW shall be in accordance with the following BNWLMA-65 Revised requirements: Design Review per QAP II, Calibration per QAP V, Nonconforming Material Control per QAP VI, and Records per QAP IX.

Particular care will be taken in the design and fabrication of the neutron multiplier assembly to assure that components have adequate structural properties. The design will incorporate features which will permit component handling with minimal hazard. 


\section{PRELIMINARY SAFETY ANALYSIS}

A. GENERAL SAFETY PLAN

The safety plan for the NMF is to 1) calculationally design and analyze for safety the neutron multiplier, 2) construct a detailed fueled mockup of the neutron multiplier, 3) experimentally make final adjustment of parameters and confirm safety (this step will be performed by qualified senior experimenters at the Critical Mass Laboratory using standard criticality measurement techniques), 4) incrementally load the multiplier into the pool at the NMF and reconfirm multiplication and other pertinent parameters in situ, 5) prepare final SAR. Calculational techniques used for the analys is in this preliminary SAR have been verified by extensive use on other systems here at Hanford. However, since these calculations had to be completed before detailed design was completed, structural material was: not included in the calculations. Therefore values of parameters should be expected to change between now and issuance of the final SAR; however, safety and general characteristics (behavior of temperature and void coefficients, etc.) will be maintained. In the long run safety in the NMF will be established and maintained by the tried and tested methods of good calculational design and analys is confirmed by experiment, followed by firm admintstrative control.

B. NEUTRON MULTIPLIER CHARACTERISTICS

General

The fuel region of the neutron multiplier will consist of aluminum-clad fuel rods in water held at a lattice spacing resulting in near optimum 
moderation. Therefore a dropped and separated element would not create a criticality hazard. Criticality will not be possible under any credible conditions. The fuel region will be annular. The region interior to the fuel annulus will be water (design will prevent insertion of a fuel element into this region) which will provide a channel around the ${ }^{252} \mathrm{Cf}$ source and the central irradiation tube. This internal water moderated region is known as a flux trap. The purpose of the flux trap is to increase the thermal neutron flux at the sample irradiation position. Characteristics of a flux trap important in design are given in the following paragraph.

Flux Trap

Consider a fuel assembly in the shape of an annulus surrounding a large voided flux trap region. Assume that moderator is added in the form of a ring on the inside of the annulus. As the moderator thickness in a flux trap is increased the thermal flux at the irradiation position in the center of the flux trap will first increase, then level out and finally decrease. This behavior of the thermal flux is primarily due to two competing effects (scattering, which slows the above thermal neutrons entering from the core, and absorption). As the moderator thickness increases the absorption effect becomes increasingly predominant. In the extreme case of a very large moderator thickness there is essentially no exchange of neutrons through the center of the flux trap. A sample inserted into the flux trap would have no reactivity effect. Therefore the thicker the moderator the smaller the reactivity effect 
of a sample in the flux trap; however, the greater the temperature and: void coefficients in the flux trap.

\section{Calculational Model}

The nuclear characteristics of several possible neutron multiplier designs were studied with the HFN and HYFN multigroup diffusion theory codes. Cross sections used in the calculations were obtained from the GAMTEC, EGGNIT and BRT-1 codes. The calculational model used was a series of nested cylindrical regions. The regions and the nomenclature which will be used in the remainder of this section are given in Figure 5 . In the model the sample region was assumed to extend the full height of the multiplier. Since the central irradiation tube will only extend down to just above the center of the fuel region this assumption overestimates sample effects. Perpendicular bucklings input to the problem were selected to simulate the effect of $6^{\prime \prime}:$ of water on the top and bottom of the multiplier. The outer water region had a minimum thickness of 6 inches in all calculations. When considering reactivity effects, $6^{\prime \prime}$ of water can be considered an infinite thickness. Thus all calculations were made with full water reflection. The multiplier found from the calculations to have the highest thermal flux combined with acceptable safety features

has the following dimensions: $R_{0}=1$ inch, $R_{1}=21 / 2$ inches, $R_{2} \cong 53 / 4$ inches. The parameters of this system will be discussed in the remainder of this section.

\section{Temperature and Void Effects}

The behavior of the temperature coefficient of reactivity for the system is shown in Figure 6 . Note that it is initially positive but turns over 
Figure 5

Regions of Calculational Model

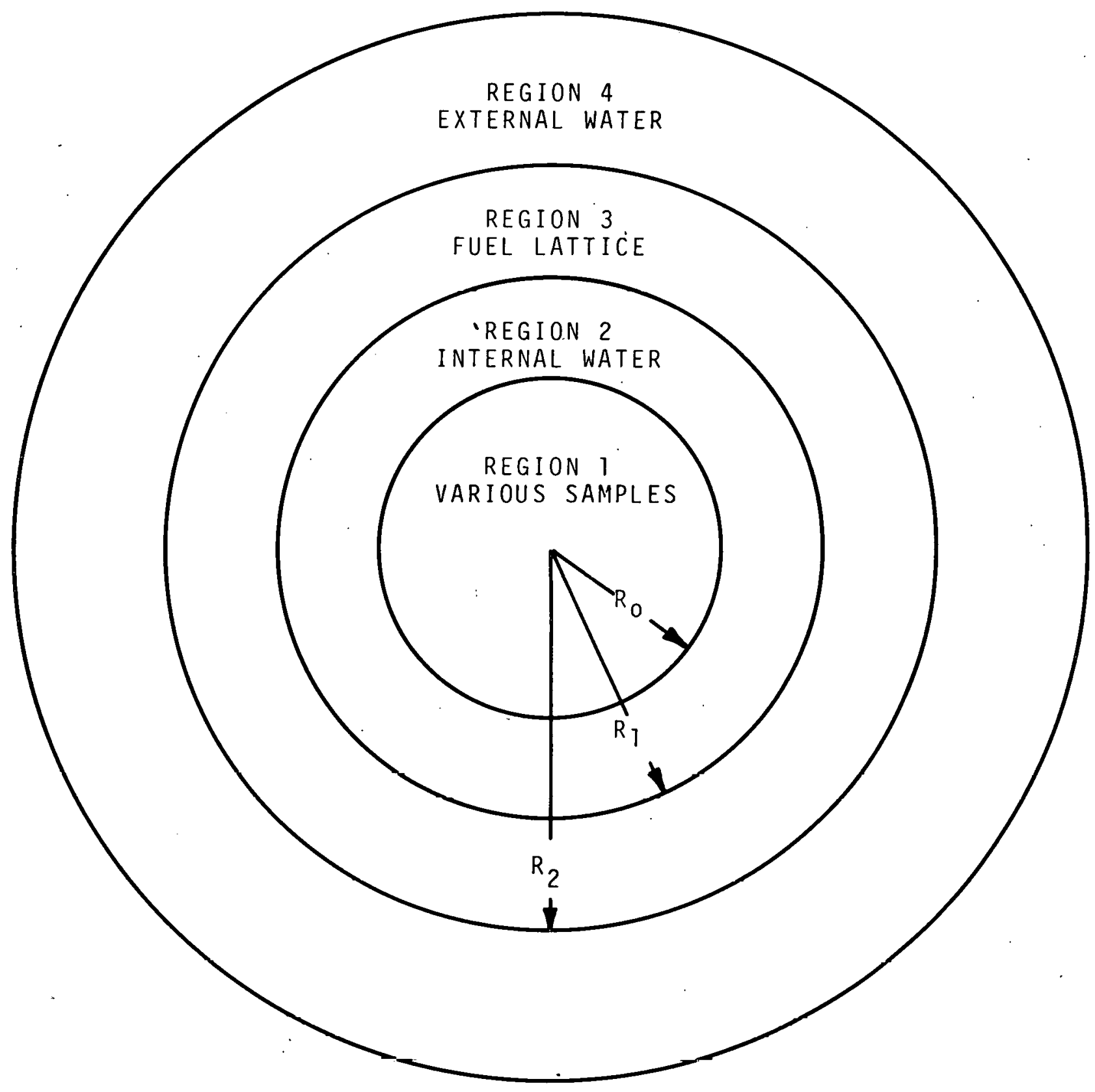

FLUX TRAP WATER THICKNESS $=R_{1}-R_{0}$ 
Figure 6

\section{Neutron Multiplier Reactivity as a Function of Temperature}

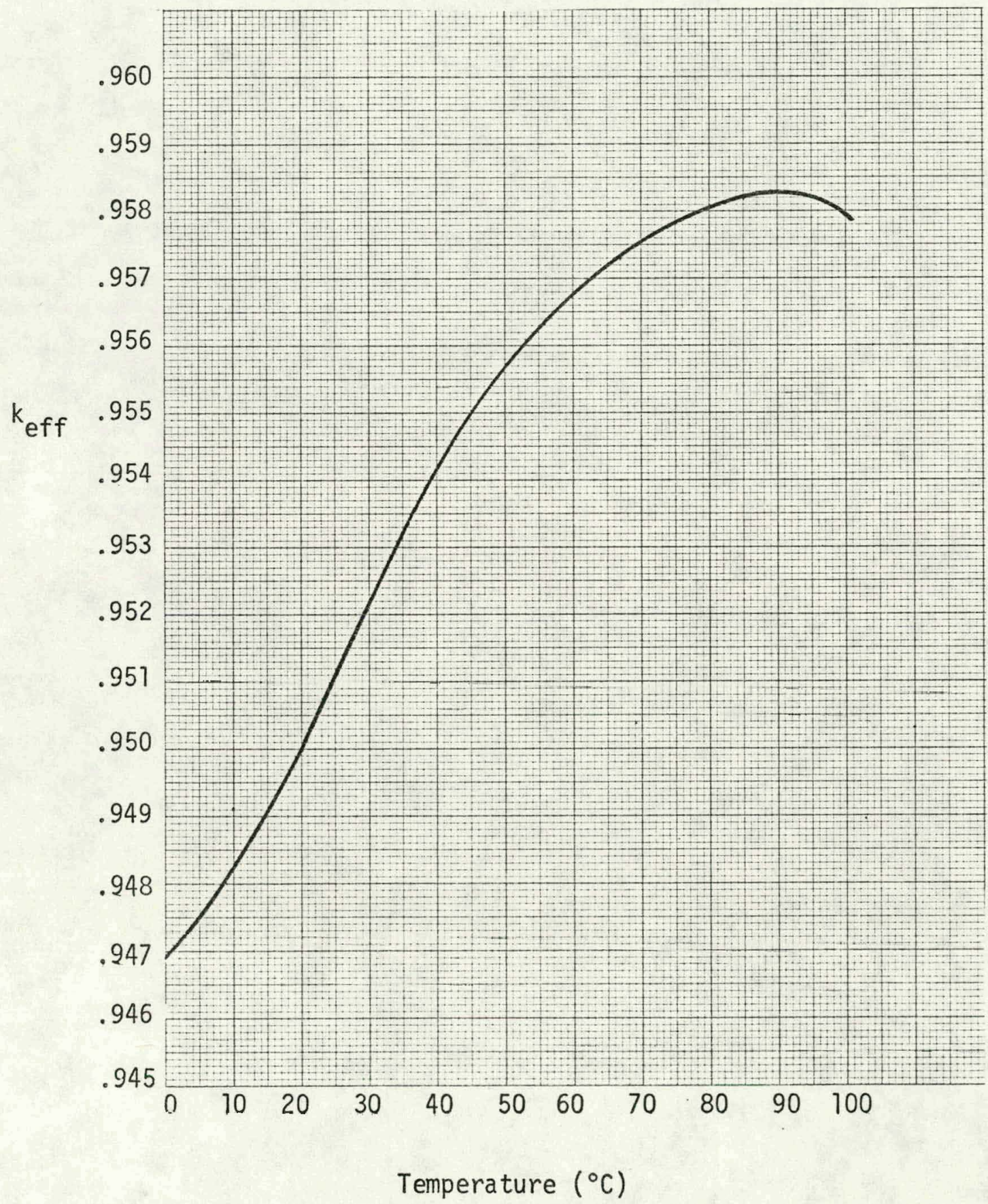


at about $90^{\circ} \mathrm{C}$ and is negative thereafter. The effects of voiding of the sample and internal water regions is shown in Figure 7 . The void coefficient exhibits the same type of behavior as the temperature coefficient. It is initially positive but turns negative before complete voiding of the water region occurs. Thus it is seen that the characteristics of the neutron multiplier make it self limiting and inherently safe for changes in the water parameters. Void and temperature reactivity effects are initially positive but reach a maximum and start decreasing while the neutron multiplier remains subcritical.

\section{Reactivity}

The neutron multiplier will be constructed to have a $k_{\text {eff }}$ of approximately 0.95-0.96 with the central irradiation tube voided and the external irradiation tubes removed. (From geometrical considerations the effect of voiding in the outer water region is to increase neutron leakage and thus decrease reactivity.) This is the most reactive credible condition of the irradiation tubes (not considering, at this time, sample effects).

C, NORMAL OPERATING CONDITIONS

The neutron multiplier has two normal states, "on" and "off". During sample irradiation the neutron multiplier will be "on" (i.e. the ${ }^{252} \mathrm{Cf}$ source will be in the center of the neutron multiplier). When no irradiation is in progress the neutron multiplier will normally be "off" (i.e. the ${ }^{252} \mathrm{Cf}$ source will be in the lowered position below the neutron multiplier). Whether the neutron multiplier is "on" or "off" the central 


\section{Figure 7}

Neutron Multiplier Reactivity as a Function of the Degree of Voiding of Regions $1+2$ (Sample and Internal Water Regions)

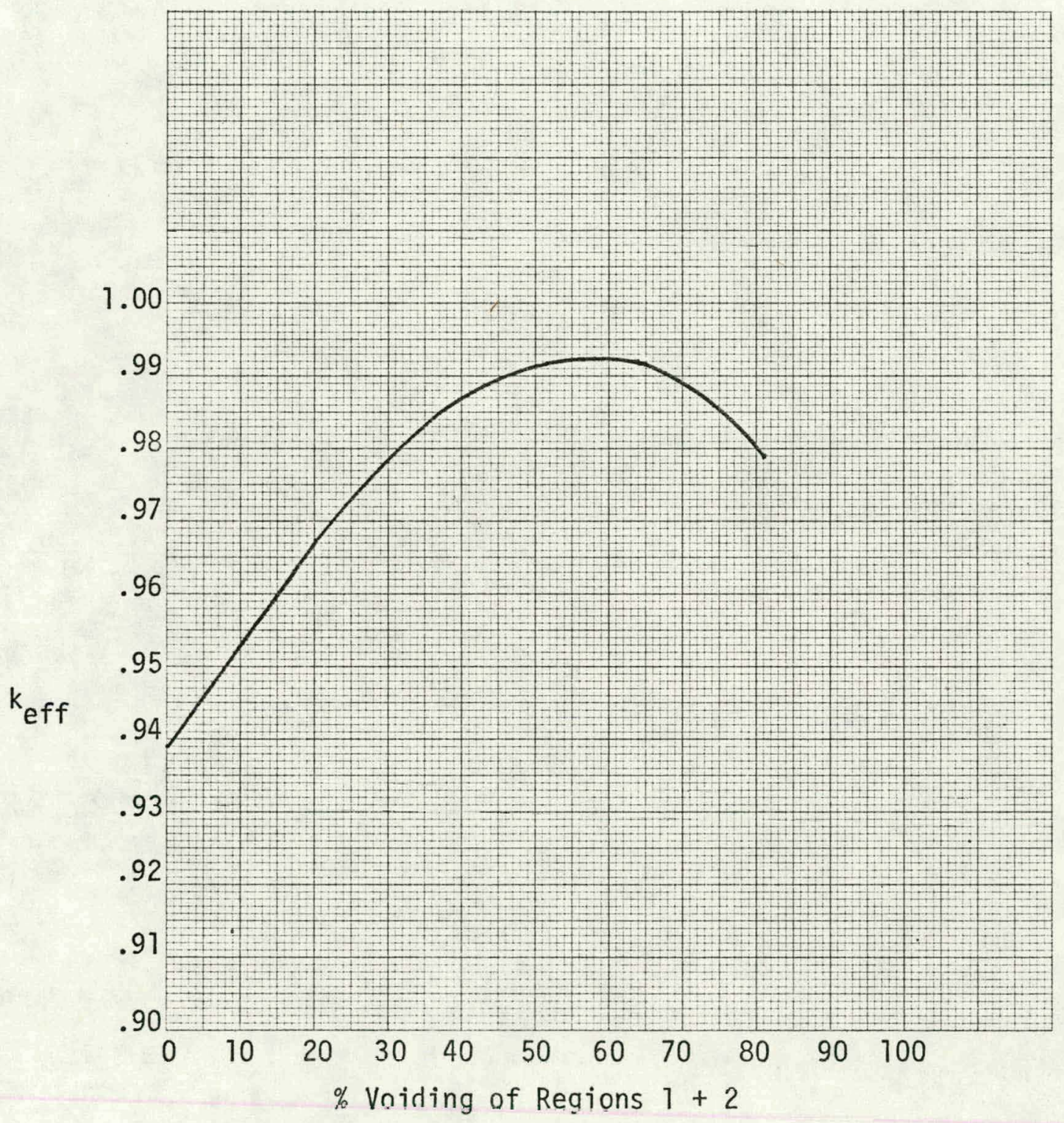


(wet) irradiation tube will be in place. Any or ail of the four 2" diameter and two 4" diameter external irradiation tubes may be in place. When the external irradiation tubes are not in place in their design positions in the neutron multiplier they are either stored in the pool next to the wall or removed from the pool. Irradiation tubes wfll not be moved during sample irradfations. Before movement of the tubes all samples will have been removed from the neutron multiplier.

Samples will only be irradiated in the sample irradiation tubes which will be located only. in their design positions. A sample may be inserted and/or removed with the neutron multiplier efther "on" or "off". There is no restriction on the number of samples that may be irradiated at any one time. There is a restriction, however, on the composition of the samples. Except in one special experiment discussed later, no non-exempt fissionable material samples shall be irradiated in the neutron multiplier. Monitoring, including a high radiatton level monitor with audible and visual alarms, shall be utilized to prevent excessive radiation exposure to personnel during sample removal and subsequent handling.

One special irradiation which may be periodically performed involves $\leq 4$ grams of ${ }^{235} \mathrm{U}$. See pages 33 and 39 for safety analysis. In this experiment the ${ }^{235} U$ metạ sample is located in an evacuated ( $\leq 2 "$ diameter) drift lube which replaces the normal sentral irradiation tube. The experiment is designed to obtain on-line mass spectrometry information on fission products. 
Normal Operating Conditions include a 20 foot depth of water in the pool. This water level is maintained by a manually operated fill system. Pool water circulation through the filter and ion exchange column will be on a schedule as "required to maintain water quality.

D. PARAMETERS UNDER NORMAL OPERATING CONDITIONS

\section{a. Radiation Parameters}

\section{General}

The maximum heat output of the neutron multiplfer will be in the range 2-10 watts. The maximum thermal neutron flux in the central irradiation tube will be of the order of $10^{10}$ neutrons $/ \mathrm{cm}^{2} \mathrm{sec}$. The nearly 16 feet of water above the fuel region of the neutron multiplier acts as an excellent radiation shield. From comparison with Bulk Shielding Reactor experimental data ${ }^{(1)}$ on radiation attenuation in water it was determined that with the sample irradiation tubes removed or flooded the radiation level at the top of the pool due to neutron multiplier operation would be less than $0.01 \mathrm{mrem} / \mathrm{hr}$. The radiation would be essentially all gamma rays.

\section{Radiation From External Irradiation Tubes}

Except for the special experiment involving irradiation of $a \leq 4$ gram uranium sample at the bottom of an evacuated drift tube, the central irradiation tube will be water-filled. (The collimated field emanating from the evacuated drift tube will be dịcussed later.) The external irradiation tubes will normally be dry. The tubes will be constructed with an offset to prevent direct radiation streaming. To calculate the radiation field emanating from an external frradiation tube, the top 
section of the tube was conservatively, represented as a straight cylindrical pipe extending down to six foot above the fuel region of the neutron multiplier (due to the shape of the irradiation tube there actualiy is more water shielding between the fuel region and the top section). It was further assumed that there is full water up to the level six foot above the fuel region and that at this point a vertfcal beam source exists. The assumption of a vertical beam source is conservattve. From the data on attenuation in six feet of water given in Reference 1, the radiation field in the top section of the tube is estimated to be approximately $10 \mathrm{mrem} / \mathrm{hr}$. The field is essentially all gamma rays and is highly collimated in the space directly above the irradiation tube,

\section{Radiation From a Voided Central Irradiation Tube}

To obtain an estimate of the radiation level which would exist at the top of the pool directly above a voided drift tube in the central irradiation position, it was assumed that the radiation emanating from the tube was that leaving a fictitious point source, located at the top of the fuel region, in a solid angle which intercepts an area equal to the cross sectional area of the drift tube at a distance equal to the spacing between the top of the pool and the fuel region. This method will result in a somewhat low answer due to neglect of radiation scatter from the water into the drift tube. However, since the tube diameter is only 2 inches and the spacing involved approximately 16 feet, the approximation should not be too bad. It was further assumed that the relative gamma ray and fast neutron doses per watt given in Reference 1 were valid. The thermal flux at the top of the fuel region was conservatively assumed to be $10^{10}$ neutrons $/ \mathrm{cm}^{2} \mathrm{sec}$. It was calculated that the dose rate in the 
beam would be approximately $150 \mathrm{mrem} / \mathrm{hr}$ with a voided 2 inch diameter tube in the central irradiation position. The radiation would be primarily thermal neutrons. This highly collimated radiation field would exist only in an approximately 2 " diameter cylindrical space directly over the tube. Skyshine would cause an increase in the background level outside of the direct beam, however, not to an extent where a health hazard would be created.

\section{${ }^{41}$ Ar Production}

Whenever an intermediate or high level neutron flux interacts with air one must consider the $(n, \gamma)$ interaction with ${ }^{40}$ Ar resulting in formation of ${ }^{41} \mathrm{Ar}$, a beta particle emitter with a 1.83 hour half life. Air contains approximately $.93 \%$ of the inert gas argon which is $99.6 \%{ }^{40} \mathrm{Ar}$. The maximum ${ }^{41} \mathrm{Ar}$ activity produced in a long term irradiation of air in a 4" diameter sample irradiation tube will be 46.5 curies. Radiation standards set the maximum permissible concentration of ${ }^{41} \mathrm{Ar}$ in air as $2 \times 10^{-6} \mu$ curies/cc. This limit is based on the assumption that a person is submersed in a semispherical infinite cloud of ${ }^{41}$ Ar for 40 hours in one week. If the ${ }^{41} \mathrm{Ar}$ were by some means removed from the irradiation tube where it presents no hazard and then uniformly distributed in the room air the resulting concentration would be approximately $1 / 10$ of the maximum permisstble concentration. Administrative control will further restrict ${ }^{41} \mathrm{Ar}$ dispersal. It is concluded that ${ }^{41}$ Ar production will nnt create a hazard. See Appendix A for further discussion of ${ }^{41}$ Ar production. 


\section{b. Reactivity Parameters}

Non-Fissile Samples

The reactivity effect of non-fissile samples in the central sample region (Region 1) was studied with diffusion theory calculations. A sample affects neutrons entering the region in 3 ways: 1) by moderation (decrease of neutron energy), 2) by absorption (removal of neutrons) and 3 ) by decreasing neutron leakage out the ends of the region (returning more neutrons to Region 2 and eventually to the fuel region). To study these effects calculations were made with several samples. Since the sample region can contain water at various effective densities (attained, e.g., by insertion of various diameter voided sample containers) the reactivity effect of water as a function of density was calculated. The results are shown in Figure 8 . To separate out the effect of neutron absorption, the water absorption cross sections were set to zero and the calculations rerun. The results are shown in Figure 9. It can be seen that the reactivity effects of water and zero absorption water are both negative; the water having, as expected, a more negative effect due to absorption of neutrons. These samples serve very well to study the effects of moderation and absorption but, because water is a strong forward scatterer, they fail to exhibit the maximum magnitude of the reactivity effect of decreasing end leakage from the sample region. To study this effect, several heavier element (non forward scatterer) samples were calculated. The results for zero absorption carbon and normal and zero absorption lead are shown in Table 1. It can be seen that these samples have a very slight ( 2 millt $k$ maximum) positive reactivity. These conservative calculations put an upper bound of approximately 
Figure 8

Reactivity Effect of a Water Sample in
Region 1 as a Function of Density

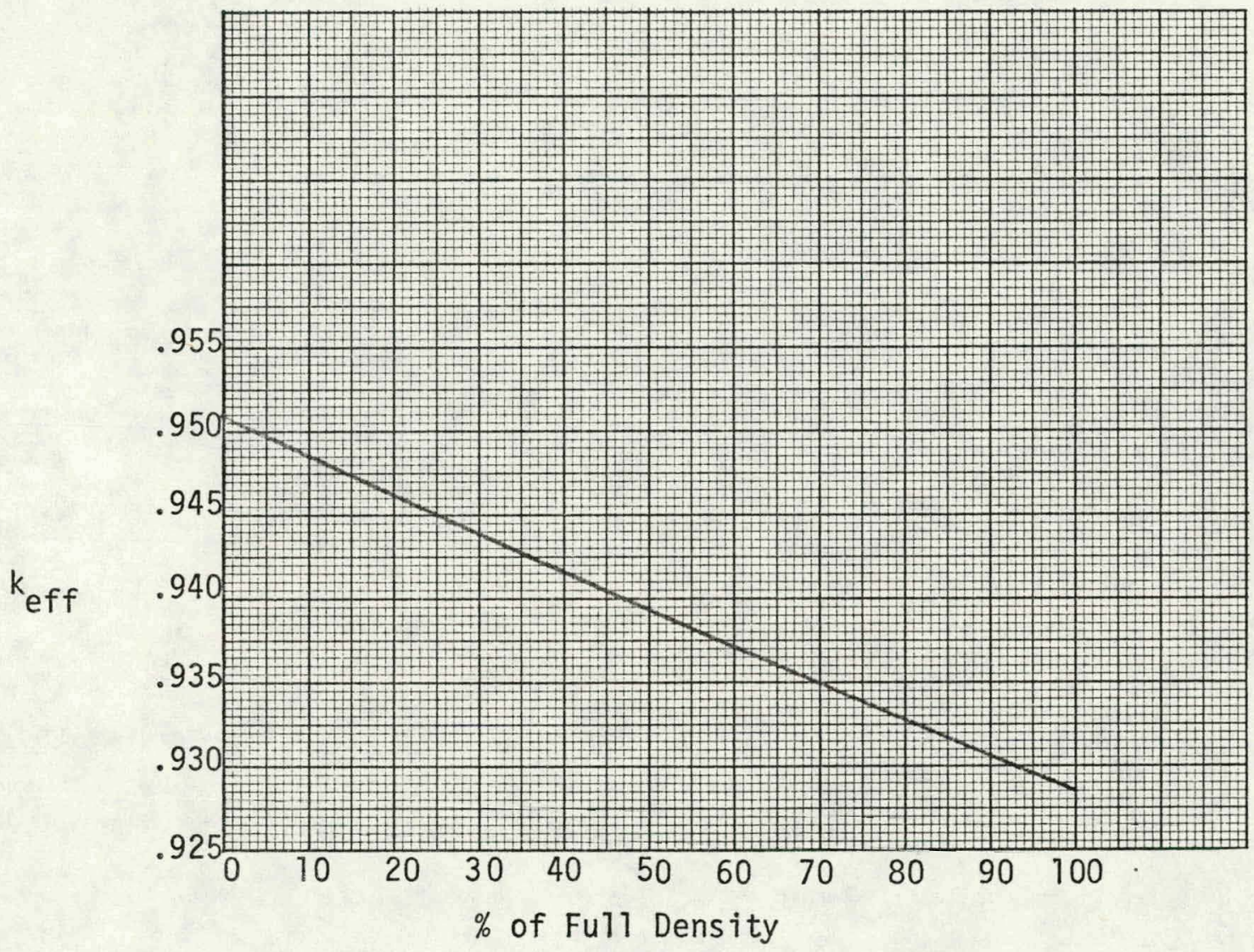


Figure 9

\author{
Reactivity Effect of a Zero Absorption Water Sample \\ in Region 1 as a Function of Density
}

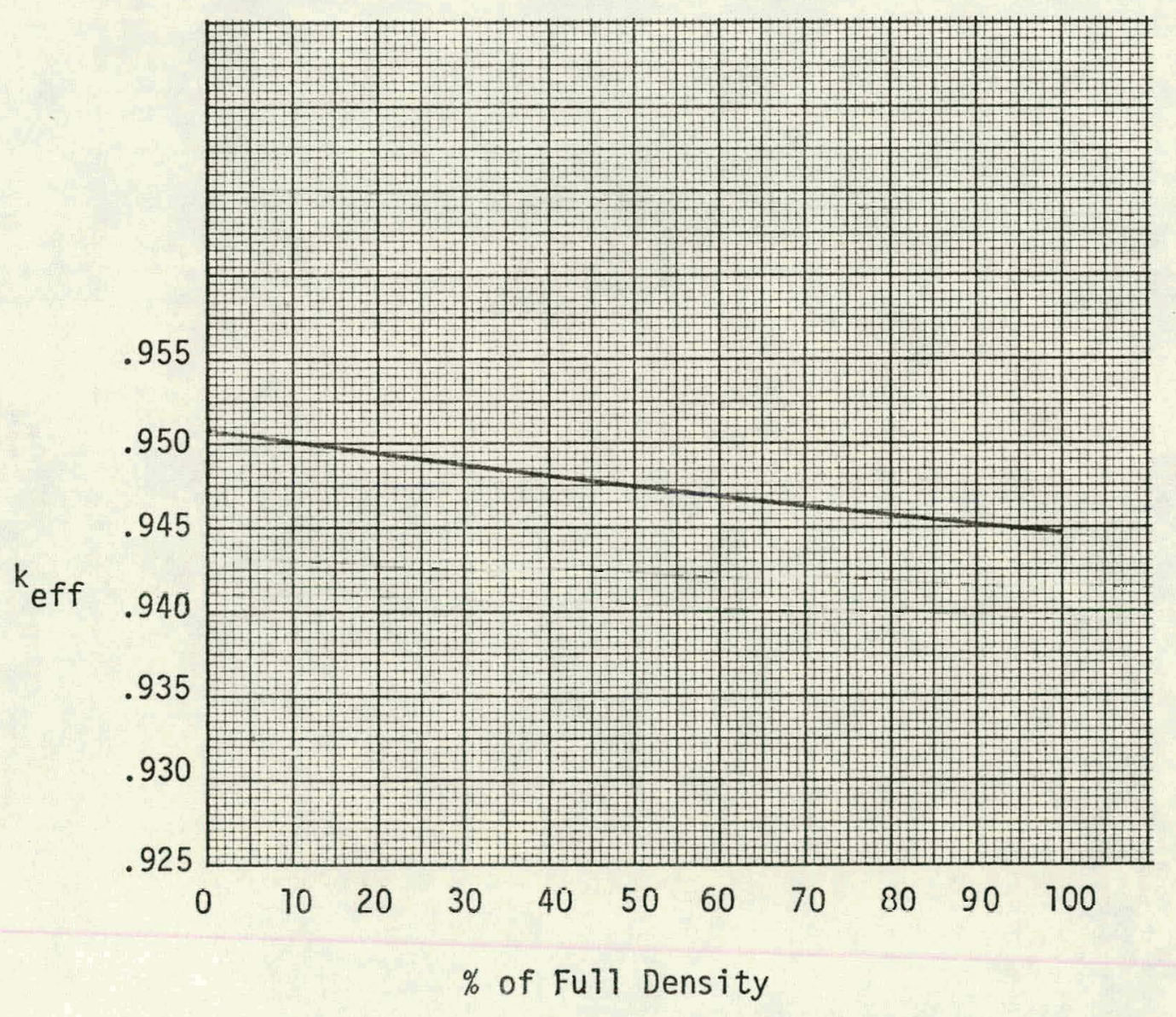




\section{Table 1}

\section{Reactivity Worth of Various Materials In Region 1}

\begin{tabular}{|c|c|c|c|}
\hline Material & $\frac{\text { Density }}{(\mathrm{g} / \mathrm{cc})}$ & $\underline{\text { keff }}{ }^{7}$ & $\underline{\Delta k e f f}$ \\
\hline Carbon $^{2}$ & 1.710 & 0.952 & 0.001 \\
\hline Carbon $^{2}$ & 1.283 & 0.952 & 0.001 \\
\hline Carbon $^{2}$ & 0.684 & 0.951 & 0.000 \\
\hline Carbon $^{2}$ & 0.128 & 0.951 & 0.000 \\
\hline Lead & 8.505 & 0.949 & -0.002 \\
\hline Lead & 0.851 & 0.951 & 0.000 \\
\hline Lead $^{2}$ & 8.505 & 0.952 & 0.001 \\
\hline Lead $^{2}$ & 0.851 & 0.951 & 0.000 \\
\hline Lead $^{2}$ & 0.085 & 0.951 & 0.000 \\
\hline
\end{tabular}


2 milli $k$ on the maximum positive reactivity effect of non-fissile samples in the central sample region. Thus irradiation of unknown but nonfissile samples in the central sample region will not significantly decrease the criticality safety margin.

Enriched Uranium Sample

To check the reactivity effect of the $\leqq 4$ gram enriched uranium sample which will be used in the special expertment, diffuston theory calculations were made with various masses of $.93 .14 \%{ }^{235} \mathrm{U}$ enriched uranium metal in Region 1. The results are shown in Figure 10. Note that the reactivity effect is positive but quite small ( $\left.\Delta k_{\text {eff }} \sim .005\right)$. Therefore the special experiment does not compromise the safety of the NMF. An adequate safety margin still exists.

\section{Sample Worth in External Irradiation Positions}

Similar reasoning can be used to determine the effect of samples in the external irradiation positions. However, the calculational analysis of the effects of samples in the external irradiation positions would require the use of a Monte Carlo code. The high cost of this analysis is not justified at this stage of the project. The reactivity effect is strongly dependent on the distance between the external irradiation tubes and the fuel region. During the third step of the general safety plan (final adjustment of parameters and confirmation of safety at the Critical Mass Laboratory) the tubes can be experimentally located to preclude exceeding $k_{\text {eff }}=0.985$ under credible conditions. 
Figure 10

Reactivity as a Function of Mass for a $93.14 \%{ }^{235} \mathrm{U}$ Enriched Uranium Sample in the Central Irradiation Position

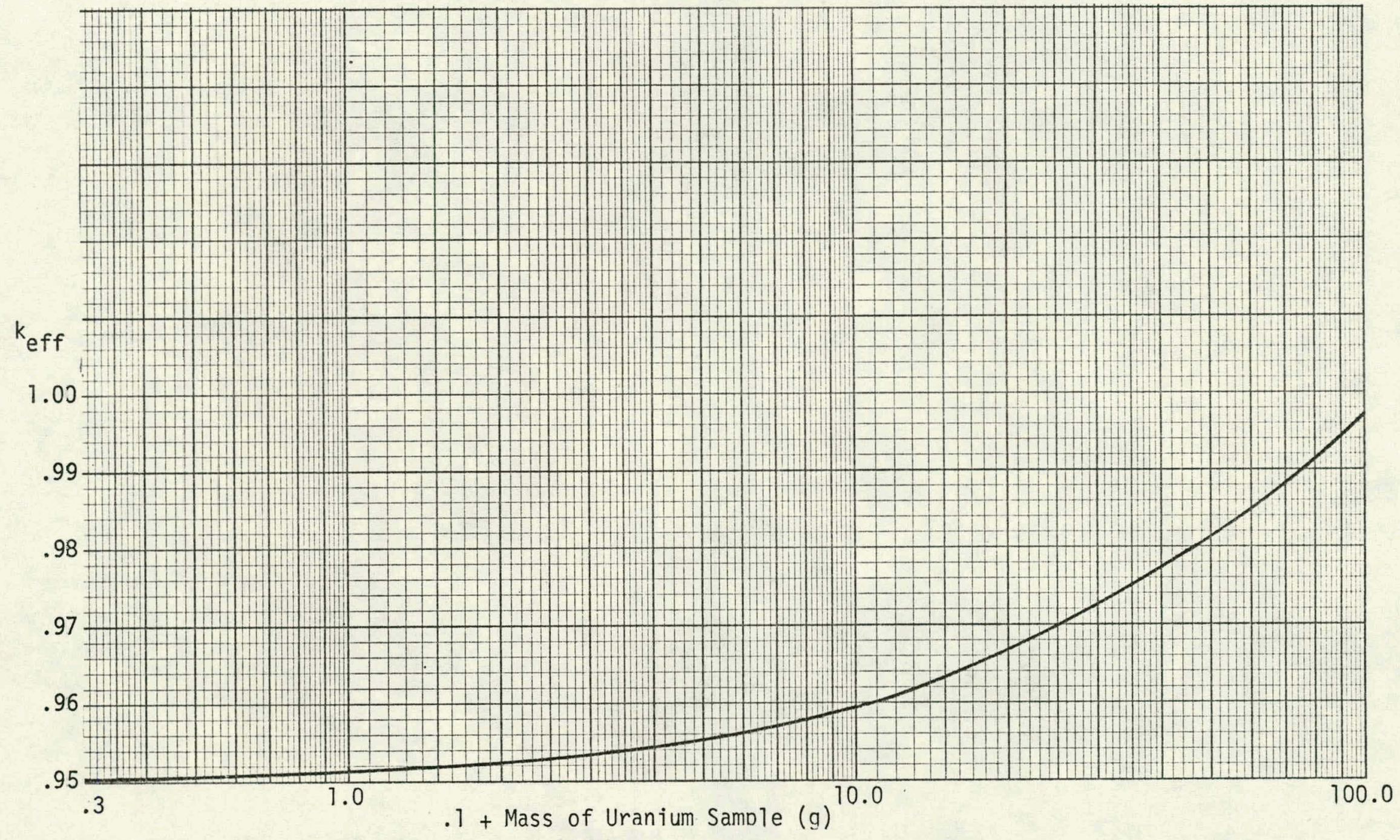




\section{E. ABNORMAL AND ACCIDENT CONDITIONS}

Improper Irradiated Sample Handling

The most credible abnormal occurrence in the NMF is improper irradiated sample handling resulting in unplanned exposure to personnel. This is because the chemical makeup of the environmental samples which will be irradiated is not completely defined. Therefore expected activities of irradiated samples cannot always be assigned with certainty. To control such exposure the NMF will contain a radiation monitor equipped with audible and visual annunciation. In addition, administrative controls and procedures will cover irradiated sample removal and handling. It is concluded that the probability and consequences of this occurrence are acceptably low.

Flooding of External Irradiation Tubes.

Damage from carelessness or accidents in irradiation tube or sample container handling could result in flooding of an external irradiation tube. Flooding of the external irradiation tubes will present no reactivity hazard. In the neutron multiplier reactivity analyses the external irradiation tubes were assumed to be removed (equivalent to flooding). The reactivity will increase due to flooding but the maximum $k_{\text {eff }}$ with any or all external irradiation tubes flooded will be 0.97 . The main hazard potential from this accident would be unplanned radiation exposure from a highly radioactive sample being irradiated in a positive buoyancy sample container whirh floats to the surface. Such exposure will also be controlled by the radiation monitor equipped with audible and visual annuciation. Administrative procedures will detail actions 
to be taken in the event of such annunciation. It is concluded that the probability and consequences of this occurrence are acceptably low. Failure to Maintain Proper Water Level

The water level in the pool will drop in time due to evaporation from the pool surface. A low water level alarm should sound before the level has dropped more than a few inches. If water is needed it may be added by opening a normally closed manual valve in the water make-up line. The person adding the water will be required to remain in the building until the proper water level is attained and the manual valve is closed. As a backup, a float switch in the pool will operate a valve in series with the manual valve to shut off the make-up water when the proper water level is attained. A very conservative calculation of evaporation from the pool under credible conditions indicates that the level would drop less than 4 inches per day. If the condition went undetected for a week the loss of water shielding would increase radiation levels at the top of the pool approximately a factor of 10 to $0.1 \mathrm{mrem} / \mathrm{hr}$. Administrative controls will require checking of the pool water level on a frequency found to detect a drop in water level before it can create a hazard. It is concluded that the probability and consequences of this misoperation are acceptably low.

If the pool were to overflow the water would flow from the floor through the floor drain into the 300 Area cold process sewer system. There will be double contingency protection against such an occurrence. Overflow of the pool could only occur due to sequential violation of administrative control and equipment failure (failure of the float switch) or 
concurrent failure of two unrelated pieces of equipment (float switch and manual valve). It is concluded that the double contingency makes the probability of this accident acceptably low. A discussion of the ${ }^{24} \mathrm{Na}$ activity which may be present in trace amounts $\left(<10^{-5} \mu \mathrm{Ci} / \mathrm{ml}\right)$ in the pool water is given in Appendix B.

The neutron multiplier pool will have a $6 "$ thick concrete wall and will be designed to withstand the earthquake described in Section IV B 3. The inside of the pool will be coated with several layers of a resin sealant to prevent leaching of materials from the concrete into the pool water. It cannot be considered totally impossible that, in spite of the multiple coats of resin, there could exist some pinholes in the liner which would allow small areas of contact of the pool water with the concrete. If it so happened that there were a hatrline crack or joint in the concrete near a pinhole, it is possible that some water could slowly leak from the pool into the ground. Particulate matter (radioactive or non-radioactive) in the water would experience a high degree of holdup and entrapment in the concrete. Further holdup and entrapment would occur in the soil. This coupled with the relatively short ( 15 hour; decays to less than $1 \%$ of the initial activity in 100 hours) half $7 \mathrm{ife}$ of ${ }^{24} \mathrm{Na}$ makes the hazard of ${ }^{24} \mathrm{Na}$ escapting the pool through its wall acceptably low at almost any concentration in the pool water. A calculation of the ${ }^{24} \mathrm{Na}$ concentration is given in Appendix $\mathrm{B}$. Introduction of Fissionable Material in Excess of Permitted Quantity Consideration must be given to the possibility of the introduction of additional fissionable material to the neutron multiplfer in the form 
of a sample. BNW Criticality Safety Procedures (BNWL-MA-25) control, on a laboratory wide basis, all handling, storage and use of 15 gram or greater quantities of non-exempt fissionable material. Essentially all fissionable materials except natural uranium and thorium are nonexempt. At this time the 329 Building is not cleared for the handling of 15 gram or greater quantities of non-exempt fissionable material. Criticality Safety Procedures for the NMF will restrict non-exempt fissionable material in the facility to only that used to fuel the neutron multiplier. NMF administrative control is more restrictive than the BNW Criticality Safety Procedures in that it allows in addition to neutron multiplier fuel a maximum of one $\leq 4$ gram sample of non-exempt fissionable material in the facility at any one time. The NMF control also requires verification of fisstonable material content prior to permitting entry of a non-exempt sample into the NMF. Thus there are two independent sets of procedures and controls (BNW Criticality Safety Procedures, NMF administrative controls) which must be violated to get a 15 gram or larger sample of fissionable material into the NMF. This more than double contingency protection, coupled with the fact that the facility mission does not include studies which would require such samples, definitely makes the risk of entry of a 15 gram or greater sample of fissionable material into the NMF acceptably low.

The NMF will be a locked facility. Only a limited number of keys for the facility shall be issued. Only trained, authorized personnel who have a work responsibility in the NMF will be allowed routine access to the area. A log will be kept showing all samples in the facility at any 
one time and noting the results of sample verification for an enriched uranium sample. However, if, in spite of these NMF controls, a 15 gram quantity of fissile material entered the NMF and was inserted into the central (most reactive) sample irradiation tube, the neutron multiplier would remain subcritical. The $k_{\text {eff }}$ attained from this violation would be less than 0.97. In fact 215 gram samples would result in a $k_{\text {eff }}$ still less than 0.98. This is true whether the samples are dry or optimumly moderated. See Figure 10 for the worth of an enriched uranium metal sample as a function of sample mass. Thus there is more than double contingency protection against criticality resulting from insertion of samples containing fissionable material. It should be emphasized that this analysis was made for the extreme case of $93.14 \%$ enriched uranium metal. The reactivity effects would be less for a lower enrichment.

Except for the special experiment with $\leq 4$ grams of enriched urantum the NMF will be primarily used for neutron irradiation of environmental samples for the purpose of activation analysis. It is credible that at some time an environmental sample might be obtained which contains natural uranium or thorium. Calculations were made to study the effect of natural uranium in the central sample irradiation tube. It was assumed that the uranium density in the environmental sample could range up to the incredibly high value of $7.1 \mathrm{~g} / \mathrm{cc}$ (the density of uranium in theoretical density $\mathrm{U}_{3} \mathrm{O}_{8}$ ). Environmental samples would normally contain much lower concentrations. The results of the calculations are given in Figure 11. Note that $7.5 \mathrm{~kg}$ of natural uranium, the quantity which 


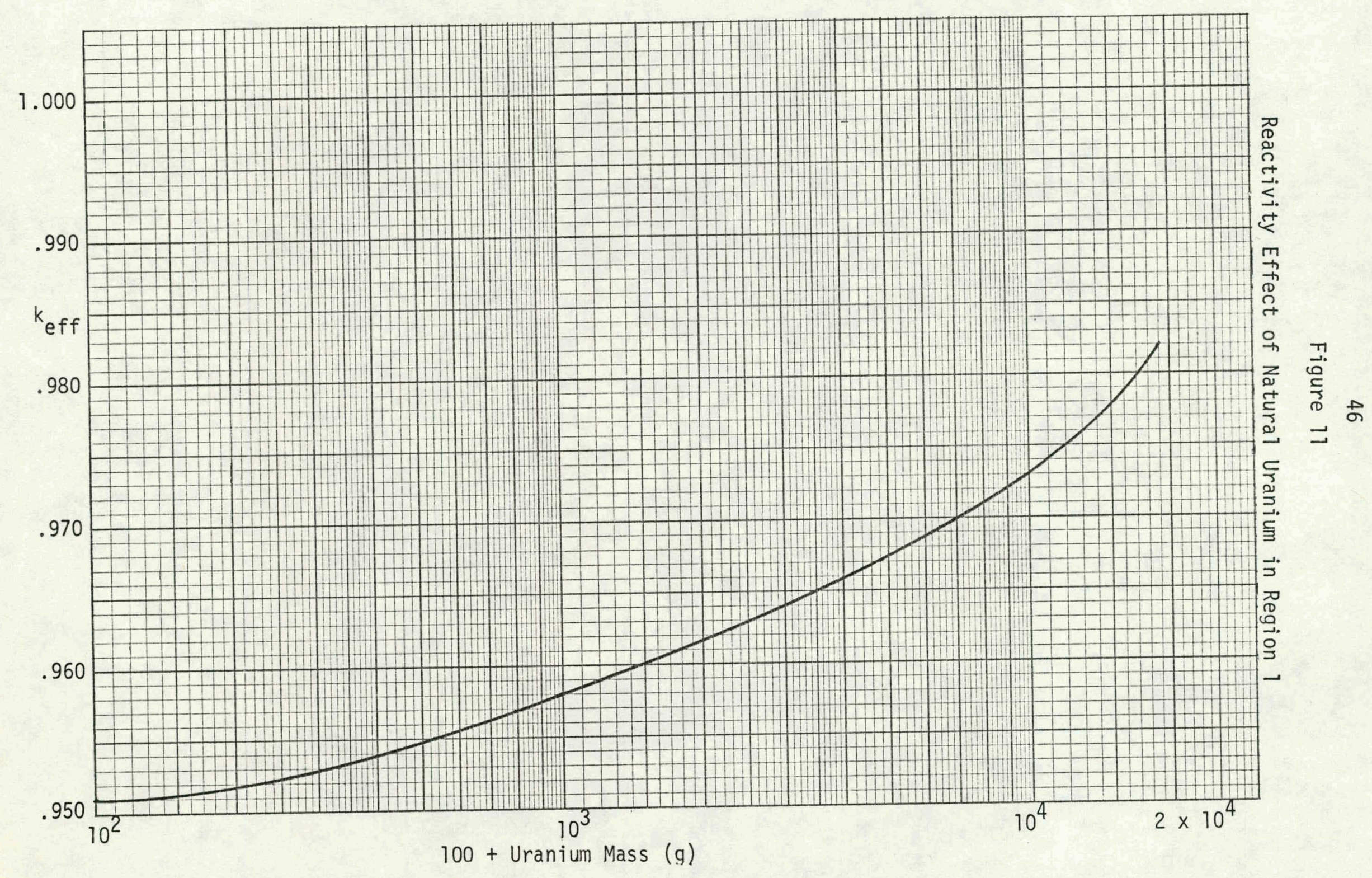


would completely fill the central irradiation tube the full length of the core at the above density, would result in a $k_{\text {eff }}$ increase to only 0.97. The effect of thorium would be simtlar. Thus no natural environmental sample, regardless of any control of samples entering the NMF, can cause criticality in the NMF.

\section{F. ADDITIONAL NMF DESIGN FEATURES BEARING ON SAFETY}

Several design features of the NMF are directed toward providing additional degrees of safety. E.g., to prevent unauthorized changes in the fuel region, the top grid plate of the neutron multiplier will restrict access to the fuel elements. The fuel elements cannot be removed without removing the top grid plate. This plate will be held in place by fasteners which can only be removed with a special tool. This tool, and the top grid plate and fuel element handling tool, will be kept locked up with the key under control of the facility supervisor. The top grid plate will be supported by rods extending from the bottom grid plate support structure. None of the top grid plate weight will be supported by the fuel elements. Thus it also will serve to protect the fuel elements from damage from an object falling into the pool. In addition, the top of the pool will normally be covered with a steel grating which will restrict objects from falling into the pool.

The only moving part of the neutron multiplier will be the motor driven source positioner mechanism. A slip clutch will prevent the source positioner mechanism from doing damage to the source or grid plate-fuel element region in the event of misalignment or jamming. 
Particulate radioactive material becoming airborne in the NMF will be negligible. The neutron multiplier will be located at the bottom of a 20 foot deep pool of water. Any particulate matter (radioactive or nonradioactive) which may be created (e.g. by leaching or corrosion) will remain in the water until it is collected on the ion exchange column in the water process system. Particulate radioactive material could be created in certain types of samples; however, administrative control on handling will make the probability of radioactive material from the samples becoming airborne in the NMF acceptably low. In addition, as further protection against the release of radioactive material which by some unforeseen series of events may become airborne, the NMF will normally be maintained at a slight negative pressure with air being drawn through a single stage HEPA filter orior to exhaustion from the building.

The purity of the water (conductivity should be in the range 3-30 $\mu$ mhos) should result in extremely long life (of the order of 10's of years) for the fuel cladding and the ${ }^{252} \mathrm{Cf}$ source cladding. The urantum-aluminum alloy fuel is clad in 40 mil minimum wall thickness aluminum. Even if the fuel clad were to be penetrated by corrosion, any leak would be of the slow pinhole variety. The ${ }^{252} \mathrm{Cf}$ is contained in fused quartz which is doubly encapsulated in stainless steel. Again, should somehow the cladding be penetrated, the leak would be of the slow pinhole variety. The filter and ion exchange column in the water process system will very efficientily remove any material in the water. Administrative controls will require periodic checking of the radiation emanating from the filter and ion exchange column. If fissionable materlal or fission products are detected action will be taken to find and eliminate their source. 
The probability of a tornado striking the NMF is extremely small. However, if the building were to be destroyed by e.g., a tornado, no nuclear, radiation, or radioactive material hazard to personnel or the environment would result. Since the neutron multiplier will be located below ground at the bottom of a 20 foot deep pool and its safety will not depend on above ground equipment or facilities, it would be virtually unaffected by complete destruction of the building.

The neutron multiplier will be housed in a mineral fiber-insulated, metal structure constructed on a reinforced concrete foundation and floor. The building will be constructed of noncombustible materials in accordance with the Uniform Building Code and will be fully protected by a wet sprinkler system. A fire alarm system wt1l be provided which will be tied into the 300 Area fire station. The building contents will be selected to minimize the combustible loading to the extent practicable. The facility mission requires the presence of only minimal quantities of combustible materials. Fire, or fire fighting, will not result in an environmental hazard. The neutron multiplier will be located at the bottom of a 20 foot deep pool of water and its safety will not depend on equipment or facilities which could be affected by fire or fire fighting.

G. PLANS FOR EVENTUAL SHUTDOWN AND DISPOSAL. OF THE NMF If at some future time the need for the neutron multiplier no longer exists, the facility may be shutdown and disposed of with minimal expenditure of time or funds. The decision on the exact steps required for shutdown and disposal will be developed when the decision is made 
to shutdown. A possible shutdown and disposal plan is given below:

a) Remove the fuel elements and ship them to a processing plant for recovery of the uranium

b) Remove and transfer the ${ }^{252} \mathrm{Cf}$ source

c) Process the pool water through the filter and ion exchanger for a sufficient length of time that dissolved or particulate radioactive material in the water is reduced to such a level that the water may be disposed of in the cold process sewer system.

d) Make required modifications to water process system and pump into cold process sewer system

e) Dispose of hardware which was situated in or close to the neutron multiplier unit as low level radioactive waste.

f) The remainder of the facility should contain only trace amounts of radioactivity. Smear and monitor the remainder of the facility to detect any concentrations of smearable or fixed radioactivity. Any material or equipment found to present a potential radiological hazard should be selectively disposed of as radioactive waste. Dispose of all uther material and equipment following the procedures used for non-contaminated materials.

g) Fill in, or install a permanent cover over, the neutron multiplier pit.

VII. CONSEQUENCES OF NUCLEAR ACCIDENTS

No credible accident in the NMF has a severity great enough to be termed a nuclear accident. Consequences of postulated credible accidents and/or abnormal conditions are given in Section VI.E. 
No contingencies arising from environmental conditions (e.g. equipment failures, water or oil flooding, fire, explosion, loss of services, earthquake, windstorm, flood) will result in a criticality hazard. Water from the neutron multiplier pool will contain trace amounts of radioactivity but this will not constitute an unacceptable contamination risk. 


\section{REFERENCES}

1. Reactor Handbook, 2nd Edition, Volume 1 Materials, C.R. Tipton Jr., Editor, 1960, Interscience Publishers Inc.

2. R. B. Richmond and C.W. Pollock, "Corrosion and Wear Surveillance in Plutonium Recycle Test Reactor Through December, 1967", BNWL-726, Battelle-Northwest, Richland, WA, July 1968. 
APPENDIX A

${ }^{41}$ Ar Production In Air Filled Irradiation Tube Or Sample Container 
Air contains approximately $0.93 \%$ of the inert gas argon which is $99.6 \%$ ${ }^{40} \mathrm{Ar}$. The $(n, \gamma)$ reaction with ${ }^{40}$ Ar yields ${ }^{41} \mathrm{Ar}$, a beta emitter with a 1.83 hour half life. ${ }^{41}$ Ar production and decay are governed by the following equations:

$$
\begin{aligned}
& \text { Rate of }{ }^{41} \text { Ar production }=\phi \Sigma_{40} V \\
& \Sigma_{40}=N_{40} \sigma_{40} \\
& \frac{d N_{41}}{d t}=\phi \Sigma_{40} V-\lambda_{41} N_{41} \\
& N_{41}=\frac{\phi \Sigma_{40} V}{\lambda_{41}}\left(1-e^{-\lambda_{41}} t_{1}\right)
\end{aligned}
$$

where $\phi=$ neutron flux

$$
\begin{aligned}
N_{40} & =\text { atoms of }{ }^{40} \mathrm{Ar} / \mathrm{cm}^{3} \text { of air }=1.81 \times 10^{17} \\
\sigma_{40} & =(n ; \gamma) \text { cross section of }{ }^{40} \mathrm{Ar}=0.64 \text { barns } \\
N_{41} & =\text { number of atoms of }{ }^{41} \mathrm{Ar} \\
\lambda_{41} & =\text { decay constant of }{ }^{41} \mathrm{Ar}=1.052 \times 10^{-4} \mathrm{sec}^{-1} \\
V & =\text { volume of irradiated air } \\
t_{1} & =\text { length of irradiation }
\end{aligned}
$$

For long irradiations $\dot{N}_{41}$ approaches the following maximum value:

$$
N_{41}^{\max }=\frac{\phi \Sigma_{40} V}{\lambda_{41}}
$$

Assume that the irradiation is terminated after a long time $t_{1}$. At time $t_{2}$ after termination the ${ }^{41}$ Ar activily will be given by

$$
\frac{d N}{d t}=-\lambda_{41} N_{41}^{\max } e^{-\lambda} 41^{t} 2
$$


The following assumptions were made in calculating ${ }^{41}$ Ar production in a capped external irradiation tube:

1) ${ }^{41} \mathrm{Ar}$ is produced during a long term irradiation at an average flux of $3 \times 10^{9}$ neutrons $/ \mathrm{cm}^{2}-\mathrm{sec}$ assumed to exist in the approximately 2 foot long portion of a $4^{\prime \prime}$ diameter irradiation tube which is adjacent to the fuel region of the neutron multiplier.

2) The ${ }^{41} \mathrm{Ar}$ will remain in the capped irradiation tube until physical action by facility personnel disturbs the conditions in the tube.* The flux of $3 \times 10^{9}$ neutrons $/ \mathrm{cm}^{2}-\mathrm{sec}$ is a conservative estimate of the average flux in the 2 foot long section of a 4 " diameter external irradiation tube. ${ }^{41}$ Ar production in the irradiation tube outside the 2 foot long section adjacent to the core will be negligible compared to production in this section. There will be no mechanism for ${ }^{41}$ Ar transport except for normal slow diffusion in stagnant uniform temperature air:

The ${ }^{41}$ Ar activity in the 4 inch diameter by 2 foot long ( $4942 \mathrm{~cm}^{3}$ volume) section is calculated to be $1.72 \times 10^{6} \mathrm{dis} / \mathrm{sec}(46.5 \mathrm{\mu}$ curies $)$ at $t_{2}=0$. In terms of concentration in the $4942 \mathrm{~cm}^{3}$ volume this is $9.41 \times 10^{3} \mu$ curies/cc. The maximum permissible concentration of ${ }^{41} \mathrm{Ar}$ in air is $2 \times 10^{-6} \mu$ curies/cc for a 40 hour week. However, this limit assumes submersion in a radioactive cloud (Argon, an inert gas is not retained in the body). Thus the volume to be considered is more properly the room volume than the $4942 \mathrm{~cm}^{3}$ volume. Uniformly distributed in the room $46.5 \mu$ curies is approximately a factor of ten below the maximum permissible concentration. The most credible

\footnotetext{
*If, at some future time, a "rabbit" (air transfer) system is needed for sample insertion and removal, consideration will be given to 41 Ar production and dispersal under moving air conditions prior to installation of the sys tem.
} 
means for the $46.5 \mu$ curies of ${ }^{41}$ Ar to get out of the irradiation tube into the room air is by removal and opening of a 2 foot long sample container following a long irradiation. NMF administrative control will require opening of sample containers in a hood whenever ${ }^{41} \mathrm{Ar}$ can be expected to be a potential hazard. Thus ${ }^{41}$ Ar production in the NMF will not create a hazard. 
APPENDIX B

Calculation of ${ }^{24} \mathrm{Na}$ Activity in Pool Water 
The pool water will contain trace amounts of ${ }^{24} \mathrm{Na}$. A beta emitter with a 15 hour half $1 \mathrm{ife},{ }^{24} \mathrm{Na}$ is produced by the $(n, \alpha)$ reaction of fast neutrons with ${ }^{27} \mathrm{Al}$. The decay product of ${ }^{24} \mathrm{Na}$ is stable. The ${ }^{24} \mathrm{Na}$ activity will remain in the pool water until it decays or is picked up on the ion exchange column. The maximum concentration of ${ }^{24} \mathrm{Na}$ in the pool water will be less than $10^{-5} \mu \mathrm{Ci} / \mathrm{ml}$ (as shown in this Appendix). Normally, with proper cleanup of the pool water, the concentration would be significantly lower, since a large portion of the ${ }^{24} \mathrm{Na}$ would be collected on the fon exchange cartridge. The ${ }^{27} \mathrm{Al}(n, \alpha){ }^{24} \mathrm{Na}$ reaction is a threshold reaction with a threshold at approximately $3.25 \mathrm{MeV}$. The cross-section is initially quite small, not reaching 1 millibarn until 5 to $6 \mathrm{MeV}$. From $6 \mathrm{MeV}$ it climbs monotonically, reaching a value of approximately 90 millibarns at $10 \mathrm{MeV}$. The maximum thermal neutron flux in the neutron multiplier will be approximately $10^{10}$ neutrons $/ \mathrm{cm}^{2} \mathrm{sec}$. The maximum flux above the ${ }^{27} \mathrm{Al}(n, \alpha)$ threshold is found from diffusion theory calculations to be approximately $2 \times 10^{8}$ neutrons $/ \mathrm{cm}^{2}$ sec. The average above threshold flux is about $3 / 4$. of this value.

Because essentially any collision of a neutron in water will degrade its energy to below the threshold, the ${ }^{27} \mathrm{Al} \cdot(n, \alpha){ }^{24} \mathrm{Na}$ reaction is only important in the fuel rod cladding. The ${ }^{24} \mathrm{Na}$ formed in the reaction will remain in the aluminum cladding until it decays or is leached into the water. Because of its low porosity there is effectively no leaching from aluminum metal. Essentially leaching will only occur in the corrosion layer of oxide formed on the surface of the rods. Therefore ${ }^{24} \mathrm{Na}$ in the water originates in a thin outer layer of the fuel cladding. This does not enter the water instantaneously but is leached out at the corrosion rate which permits 
some of the ${ }^{24} \mathrm{Na}$ to decay prior to entering the water. Corrosion rates observed in the PRTR ${ }^{(2)}$, under conditions which were more favorable for corrosion than those that will exist in the neutron multiplier pool, were less than $0.1 \mathrm{mils} /$ year.

Assumptions made in, and details of, the calculation of the ${ }^{24} \mathrm{Na}$ activity concentration are given below:

$R=$ Reaction Rate $/ \mathrm{cm}^{3}=\phi N_{A T} \bar{\sigma}$

The flux above the $\left.{ }^{27} A\right](n, a)$ threshold is assumed to be $2 \times 10^{8}$ neutrons $/ \mathrm{cm}^{2} \mathrm{sec}$.

The spectrum weighted average cross section is assumed to be 10 millibarns.

$$
\begin{aligned}
& N_{A 1}=6.0 \times 10^{22} \text { atoms } / \mathrm{cm}^{3} \\
&=6 \times 10^{-2} \text { atoms } / \text { barn }-\mathrm{cm} \\
& R=\left(2 \times 10^{8}\right) \cdot\left(6 \times 10^{-2}\right)\left(10^{-2}\right) \cdot\left(3.6 \times 10^{3}\right) \\
&=4.32 \times 10^{8} \text { atoms of }{ }^{24} \mathrm{Na} \text { produced } / \mathrm{cm}^{3} \mathrm{hr}
\end{aligned}
$$

At equilibrium in the aluminum

$$
\begin{aligned}
& \frac{\mathrm{d} \mathrm{N}_{24}}{\mathrm{dt}}=4.32 \times 10^{8}-\lambda \mathrm{N}_{24}=0 \\
& \mathrm{~N}_{24}=\text { atoms of }{ }^{24} \mathrm{Na} / \mathrm{cm}^{3} \\
& \lambda=\frac{\ln 2}{\text { half } 11 \mathrm{fe} \text { of } 24 \mathrm{Na}}=4.62 \times 10^{-2} \mathrm{hr}^{-1} \\
& =1.283 \times 10^{-5} \mathrm{sec}^{-1}
\end{aligned}
$$




$$
\begin{aligned}
\therefore N_{24} & =\frac{4.32 \times 10^{8}}{4.62 \times 10^{-2}}, \\
& =9.35 \times 10^{9} \text { atoms } / \mathrm{cm}^{3}=\begin{array}{l}
\text { equilibrium concentration of } \\
\text { in aluminum clad }
\end{array}
\end{aligned}
$$

Assume that the corrosion rate of aluminum is $0.1 \mathrm{mils} /$ year $=$

$$
2.9 \times 10^{-8} \mathrm{~cm} / \mathrm{hr}
$$

$V=$ Volume of material removed from rods $/ \mathrm{hr}$

$=$ (no. of rods) (rod length) $\pi\left[(\text { radius of rod })^{2}-(\right.$ radius of rod corrosion rate in $\mathrm{cm} / \mathrm{hr})^{2}$ ]

Assume that the multiplier will contain 280 rods each with OD of $0.4 "$ and length of $22 "$

Substituting in these values yields

$$
\begin{aligned}
V & =1.45 \times 10^{-3} \mathrm{~cm}^{3} / \mathrm{hr} \\
P & =\text { quantity of }{ }^{24} \mathrm{Na} \text { entering water } / \mathrm{hr}=\mathrm{N}_{24} V \\
& =1.36 \times 10^{7} \text { atoms } / \mathrm{hr}
\end{aligned}
$$

At equilibrium in the water

$$
\begin{aligned}
& \frac{\mathrm{d} \mathrm{N}_{24}{ }^{1}}{\mathrm{dt}}=P-\lambda \mathrm{N}_{24}{ }^{1}=0 \\
& \text { where } \mathrm{N}_{24}{ }^{1}=\text { atoms of }{ }^{24} \mathrm{Na} \text { in the water } \\
& \mathrm{N}_{24}{ }^{1}=\frac{\mathrm{P}}{\lambda(\mathrm{hr}-1)}=\frac{1.36 \times 10^{7}}{4.62 \times 10^{-2}}=2.94 \times 10^{8} \text { atoms at equin ibrium } \\
& \text { Activity }=\lambda\left(\mathrm{sec}^{-1}\right) \mathrm{N}_{24}{ }^{1}=\left(1.283 \times 10^{-5}\right)\left(2.94 \times 10^{8}\right) \\
& =3.77 \times 10^{3} \mathrm{dis} / \mathrm{sec} \\
& =0.102 \text { micro curies }
\end{aligned}
$$

Volume of water in $5^{\prime}$ diameter $\times 20^{\prime}$ deep pool $=11120$ liters $\therefore{ }^{24} \mathrm{Na}$ activity/l $=.92 \times 10^{-5} \mu$ curies $/ \ell$ 